تأثير برنامج باستخدام تمرينات TABATA على تنمية اللياقة البلنية الخاصة ومستوي أداء بعض المهارات الاساسية في التمرينات الفنية

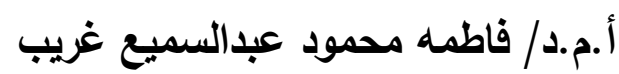

أستاذ مساعد بقسم المناهج وطرق تدريس التربية الرياضية

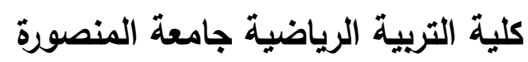

مقدمة ومشكلة البحث

إن الزيـادة الهائلـة فى حجم المعرفـة العلميـة والبشـرية ومـا يحدث مـن ثورة فى مجـال

المعلومات إمتدت إلى جميع فروع ومجالات العلوم المختلفة مما يسمح لنا بمتابعة هذا التوسع والتطور ونسايره ونتعايش معه ونحاكيه حتى نصبح جزءا لا يتجزأ من حياة المجتمعات الحديثة، وتعتبر التربية الرياضية مجالا تربويا هاما كصورة بعكس من خلالها مدى التقدم، فقد حظيت بـه

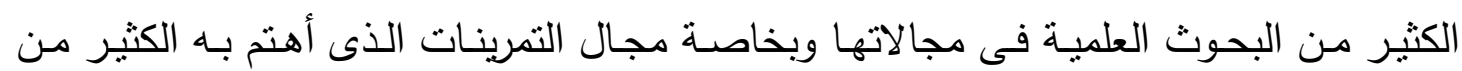
العلماء وساهموا فى تقدمة وتطوره.

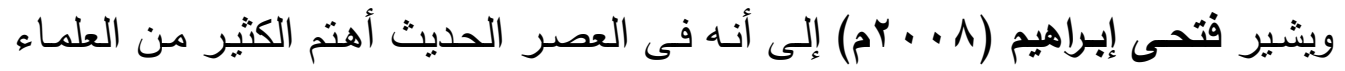

بوضع أساليب وأسس تحقق أغراض التمربنات باعتبارها الأساس والأصل لكل الحركات البدنية.

Tabata ومن أساليب التمرينات التي ظهرت مؤخرا لتتمية اللياقة البدنية تمرينات تاباتا

وهي نوع من التمرينات عالية الكثافة تعتمد علي ممارسـة التمارين الرياضية لفترات قصيرة تليها فترة راحة في جلسة تمتد من ه دقائق الي • ب دقيقة ، فهي تعمل علي اكساب الجسم لياقة بدنية

عالية وتحسن أداء القلب والاوعية الدموية وتحسن الايض وزيادة حرق الدهون.(r) وظهرت تمرينات TABATA لاول مرة في دراسة عن الالعاب الاوليمبية للعالم الياباني

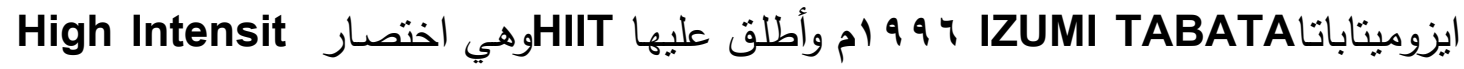
"interval Training لمدة • ب ثانية أداء يليها · • ثواني راحة وتكرار ^ مجموعات باجمالي ؛ دقائق للتمرين تعمل علي تحسين القدرة الهوائية واللاهوائية واستهلاك الحد الاقصي من الاوكسجين.)

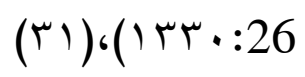

وتعتبر تمرينات TABATA من أفضل اساليب التدريب، وتتمتع بالسهولة والبساطة ، ولا

تحتاج الي معدات أو مكان خاص محدد للتدريب، ولا تحتاج للكثير من الوقت للتدربب ، ومع

$$
\text { ذلك تحصل علي نتائج جيدة.( } 9: 24 \text { ( ) }
$$

ويشير هوارد فورتثر وآخرون Howard Fortner,et,al 1 ( • rم)،تالسبا/مبرتس 


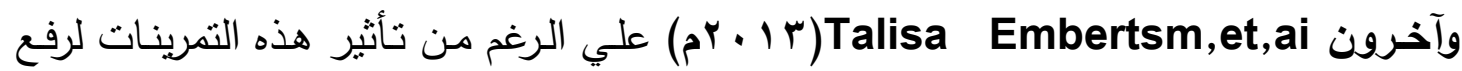
الكفاءة البدنيـة والمهاريـة الا انـه مـازال هنـاك قدر ضئيل جدا مـن الدراسـات المتعلقة بفاعلية

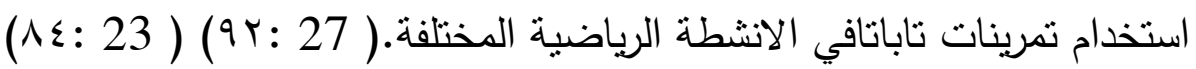

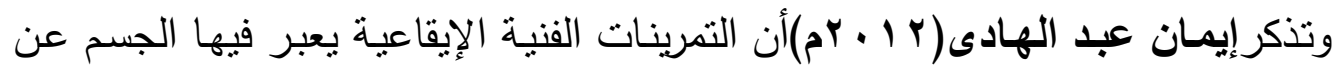

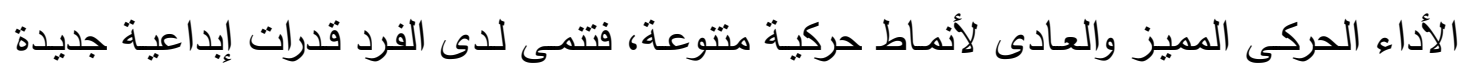
معتمده على إمكانياتة الفردية بحيث يصل بهذه القدرات إلى كفاءة ومهارة أكثر إحساسا وتعبيرا. $(10: 1)$ وتضيف عطيات خطاب (99V ام) أنها تؤدى بإستخدام أو بدون الأدوات اليدوية، ولا

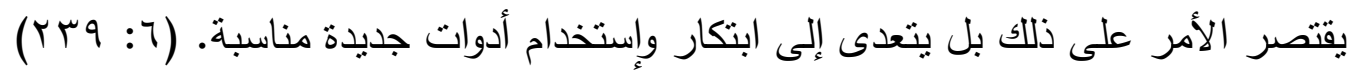

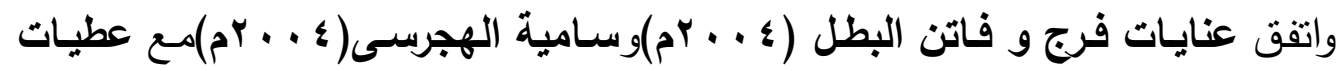

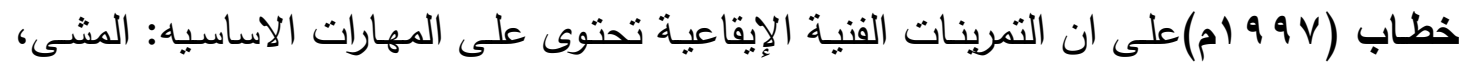

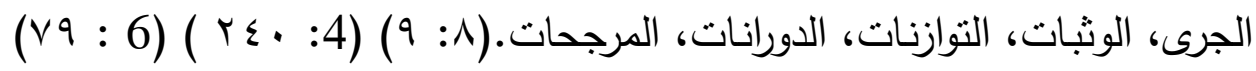

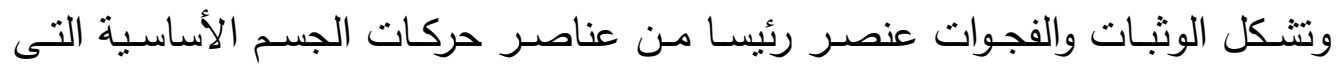

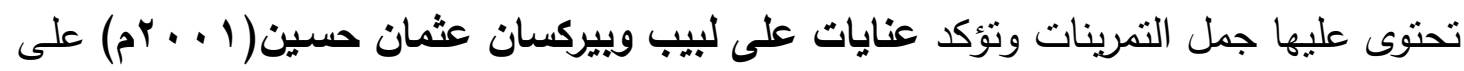

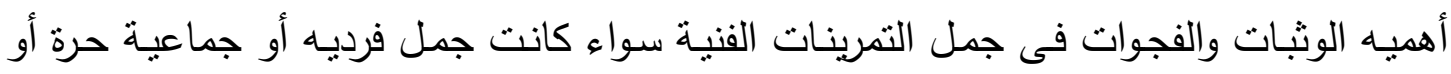

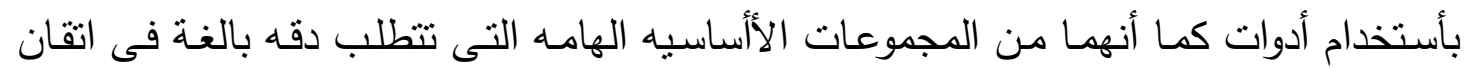

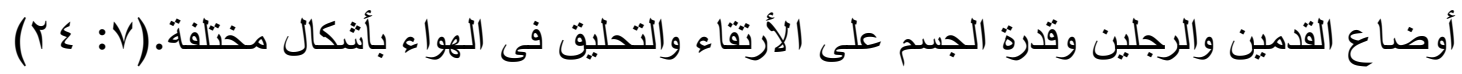

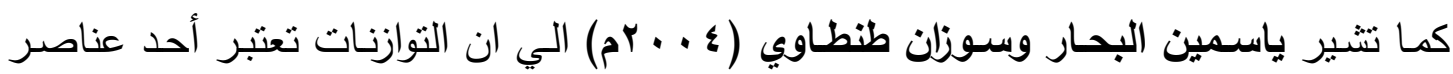

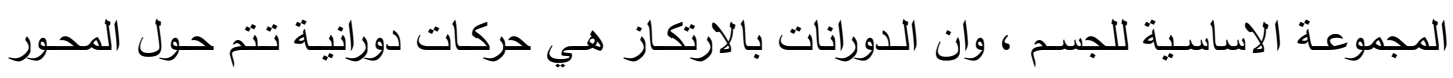
الطولي لجسم الطالبة ويتم تتفيذها علي رجل واحدة ، ويرتبط كل من مكون التوازن ومكون

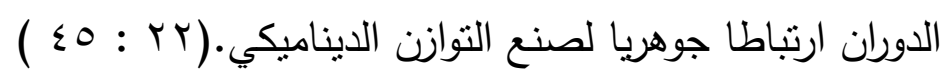

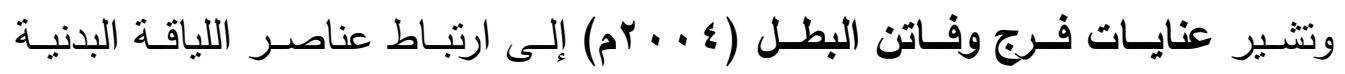

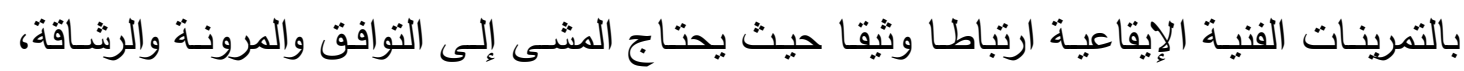

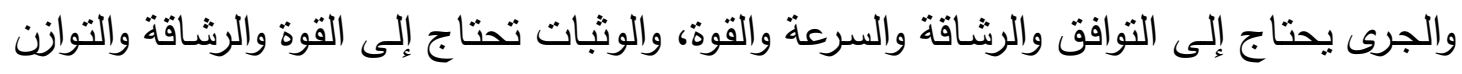

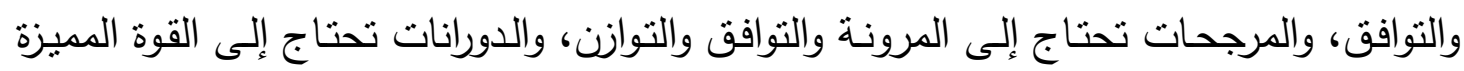

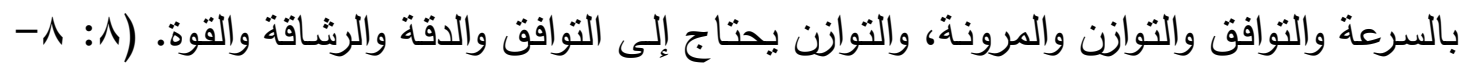

والتمرينات الفنية الإيقاعية إحدى الدقررات الدراسية التطبيقية الدقررة على الطالبات فى

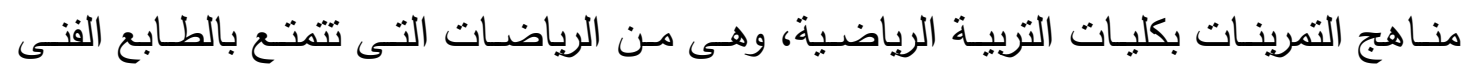


والإيقاعى الجمالى لما تحتويه من المهارات الحركية المميزة والعناصر المحتلفه البدنية والمهارية

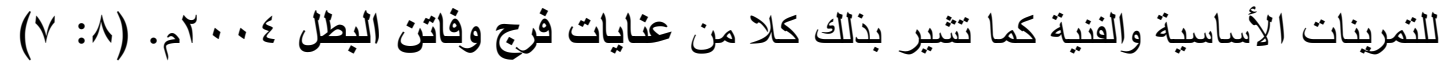
ومن خلال عمل الباحثة فى مجال التدريس والأشراف على مقررات التمرينات لطالبات الفرقة الأولى والثانية بكلية التربية الرياضية جامعه المنصورة فقد وجدت أن مستوى الأداء الفنى للوثبات (الليب- النجمـة- المـوزة) والتوازنـات (ميززان أمـامي -ميزان الركبـة) والدورانات(الدوران بالتقاطع -دوران باسية) وهى من المهارات الأساسية للتمرينات الفنية الإيقاعية ليس على الوجة المرضسى رغم ما يبذل معهن من استخدام طرق وأسـاليب تدريس وتدربيات منتوعة، وإستخدام وسائل الإيضاح والأدوات المعينة المناسبة، مما دعىالباحثة لاستخدام الاسلوب العلمى للتعرف على مستوى ادائهن لهذة المهارات، وقد استلزم ذلك دراسه استطلاعيه لنسب تقديرات مستوياتهن للحكم عليهن بشكل موضوعى من خلال تحليل نتائج طالبات الفرقة الأولى فى مقرر التمرينات

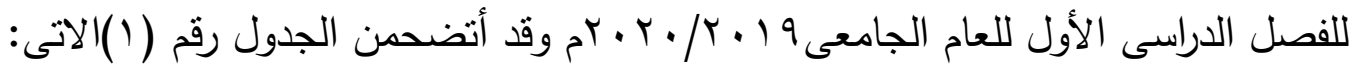

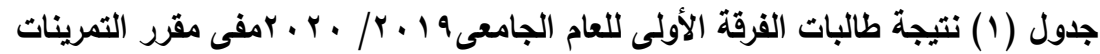

\begin{tabular}{|c|c|c|c|c|c|c|c|}
\hline المجموع & امتياز & جياجلا & جيل & مقبول & ضعيف & ضعيف جدا & التقدير \\
\hline 505 & 5 & 100 & 135 & 58 & - & 196 & الطالبات \\
\hline$\% 1 \ldots$ & $\% .9$ & $\% 19.8$ & $\% 26.7$ & $\% 11.4$ & - & $\% 38.8$ & النسبة \\
\hline
\end{tabular}

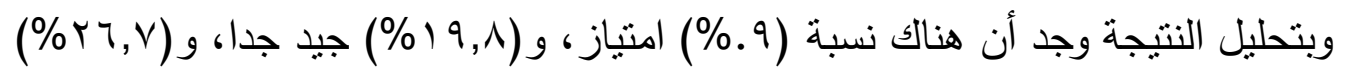

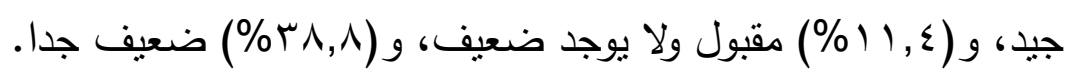

وقد أرجعتالباحثة التفاوت فى نتائج هذه الدراسة إلى القصور فى بعض عناصر اللياقة البدنية الخاصة المرتبطة بأداء بعض المهارات الأساسيه مما حذا إلى العمل على إيجاد أسلوب لرفع مستوى مجموعة المتغيرات البدنية التى تساهم فى أداء هذه المهارات لدى الطالبات، والذى قد يتمثل فـى أسـلوب تمرينـات TABATA وكمحاولـة للتعـرف على تأثثر برنـامج تمرينـات على مستوى أداء بعض المهارات الأساسية فى التمرينات الفنية (الوثبات- التوازنات بــ TABATA - الدورانات) لطالبات كلية التربية الرياضية جامعه المنصورة. أهدف البحث

يهدف البحث إلى التعرف على تأثثر برنامج تمرينات TABATA على تتمية عناصر

اللياقة البدنية الخاصة ومستوي أداء بعض المهارات الأساسية فى التمرينات الفنية . فروض البحث

ا-توجد فروق دالة إحصائياً بين متوسطات القياسين القبلي والبعدي للمجموعة التجربيية فى مستوى اللياقـة البدنيـة الخاصـة ومستوي أداء المهارات الأساسية فى التمرينـات الفنية قيد البحث لصالح القياس البعدى. 
r-توجد فروق دالة إحصائياً بين منتوسطات القياسين القبلي والبعدي للمجموعة الضابطة

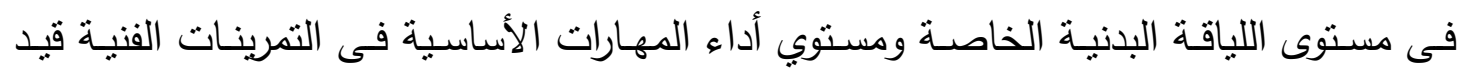

$$
\text { البحث لصالح القياس البعدى. }
$$

ب-توجد فروق دالة إحصائيا بين منتوسطات القياسين البعديين بين المجموعة التجريبية

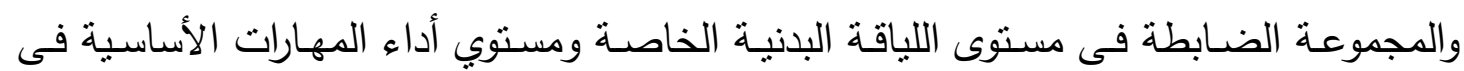
التمرينات الفنية قيد البحث لصالح القياس البعدى للمجموعة التجريبية.

مصطات البحث

تمرينـات (TABATA):وهي نوع من انواع التمارين تعدل علي تحسين القدرة الهوائية

واللاهوائية ذات شدة عالية وفترات راحة لفترة منتوسطة ـ ب دقيقة ـ(تعريف اجرائي)

إجراءات البحث:

\section{منهج البحث}

استخدمت الباحثة المنهج التجريبى وذللك باستخدام أسلوب التصميم التجريبي لمجموعتين

$$
\begin{aligned}
& \text { إحداهما تجريبية والأخرى ضابطة. } \\
& \text { مجتمع وعينة البحث : }
\end{aligned}
$$

يمثل مجتمع البحث طالبات الفرقة الثانية بكلية التربية الرياضية بجامعة المنصورة للعام

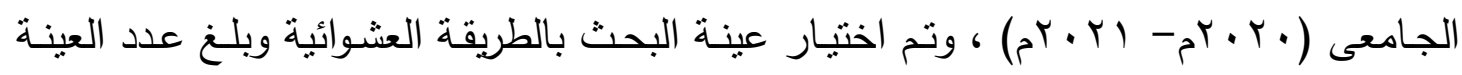
الأساسية (rT) طالبة، تم تقسيمهن إلى مجموعتين مجموعة تجربيية قوامها (T ( ) طالبات وتم تطبيق البرنـامج المقترح TABATA عليها ومجموعـة ضـابطة قوامها (7 ( ) طالبـات وتم تطبيق

\begin{tabular}{|c|c|c|c|c|c|c|}
\hline معامل الالتواء & الالمعراف & الوسيط & المتوسط & وحدة & المتغيرات & المتغيرات \\
\hline $1,1 \wedge r$ & . & 11 & $1 \Lambda, \leqslant \mu v$ & 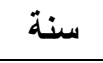 & 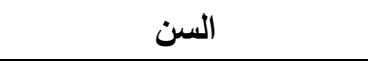 & \multirow[t]{3}{*}{ الاساسية } \\
\hline$\cdot 941$ & r, & 17. & $17 ., 9 \mathrm{rv}$ & 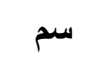 & الطول & \\
\hline •, & $0, r Y \wedge$ & 7,0 & $7, Y \cdot Y$ & 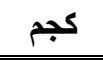 & 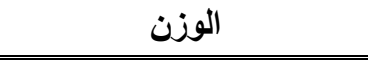 & \\
\hline ( ) & $\cdot, v_{0}$ & r & $1, \Lambda 1 r$ & عدد & التوافق "الذراعين مع الرجلين" & \multirow[t]{6}{*}{ البذنية } \\
\hline$\cdot, Y \otimes V$ & $1, \leq Y \leq$ & ir & $I Y, I \wedge V$ & عدد/ث & القوة "عضلات البطن" & \\
\hline . & $\cdot, \wedge 17$ & $\bullet$ & $\bullet$ & عدد/ث & 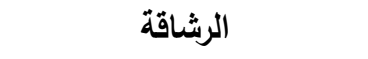 & \\
\hline$\cdot, \cdot \vee \vee \bullet-$ & $r, \vee 9 \wedge$ & 01,0 & $01, r \mid r$ & عدد/ث & المرونة "الجذع" & \\
\hline$\cdot, .0 \leqslant$ & $\varepsilon, \vee \wedge \varepsilon$ & r & $r 1, r \mid r$ & 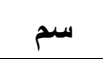 & المرونة "الحوض" & \\
\hline$\cdot, 7 \leqslant \vee$ & $\cdot, \vee \vee 9$ & r,qvo & $\varepsilon, \ldots \wedge$ & عدد/ث & التوازن "الثابت" & \\
\hline
\end{tabular}
البرنامج المتبع بالكلية، تم اختيار عينة استطلاعية بالطريقة العشوائية قوامها ( • ج) طالبة .

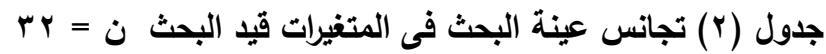




\begin{tabular}{|c|c|c|c|c|c|c|}
\hline., $.71-$ & $1, r \leq$. & rr & $r 1,9 r v$ & 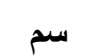 & القدرة العضلية "للرجلين" & \\
\hline . , \& TY- & $\cdot, r \ldots$ & . 4 &., 711 & درجة & وثبة التجمة & \multirow[t]{7}{*}{ المهارية } \\
\hline$\cdot, I r v-$ & $\cdot, 10 \mathrm{~V}$ &.,$\infty 0$ & ו, ו & درجة & وثبة الموزة & \\
\hline . & . & $\cdot r$ & ., rqu & درجة & وثبة الليب & \\
\hline$\cdot, \varepsilon V$ &., 1 &.,$r^{\prime}$ & $\cdot, r \varepsilon$ & درجة & ميزان امامي & \\
\hline$\cdot, 1 \cdot-$ & $\cdot, 11$ & $\cdot, 7$ & $\cdot, \diamond \mathrm{V}$ & درجة & ميزان ركبة & \\
\hline.,+1 &., 11 & . &., 00 & درجة & دوران بتقاطع القدمين & \\
\hline$\cdot,\{\wedge-$ & $\cdot, 1$ & $\cdot, r q$ & $\cdot, r \varepsilon$ & درجة & دوران باسية & \\
\hline
\end{tabular}

يتضـح من جدول (Y) أن جميع قيم معاملات الالتواء المحسوبة لقياسـات المتغيرات قيد البحث

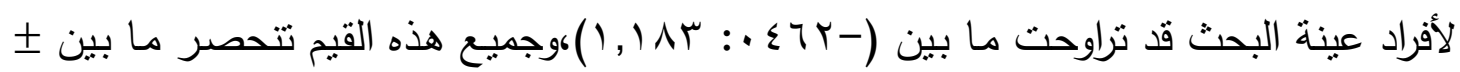
r مما يدل ذلك على تجانس أفراد عينة البحث فى تللك المتغيرات. جدول (r)التكافؤ بين مجموعتى البحث (التجريبية - الضابطة) في المتغيرات قيد البحث $17=r_{\dot{U}}=10$

\begin{tabular}{|c|c|c|c|c|c|c|c|}
\hline \multirow{2}{*}{$\mathbf{T}$} & \multicolumn{2}{|c|}{ المجموعة الضابطة } & \multicolumn{2}{|c|}{ المجموعة التجريبية } & \multirow{2}{*}{ وحدة } & \multirow{2}{*}{ الاختبارات } & \multirow{2}{*}{ المتغيرا } \\
\hline & انحراف & متوسط & انحراف & متوسط & & & \\
\hline $\begin{array}{c}- \\
\cdot, \text {, ז }\end{array}$ & $\begin{array}{c}\cdot, V_{0} \\
0\end{array}$ & $1 \wedge, 0$. & $\begin{array}{c}., 01 \\
v\end{array}$ & $i \Lambda, r \vee \Delta$ & سنة & 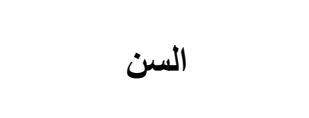 & \multirow{3}{*}{ الاساسية } \\
\hline $\begin{array}{c}- \\
\cdot, 171\end{array}$ & $\begin{array}{c}r, r q \\
q\end{array}$ & $\begin{array}{c}17 \cdot, \mathrm{AV} \\
0\end{array}$ & $\begin{array}{c}r, V V \\
\varepsilon\end{array}$ & $\begin{array}{c}19 ., 7 r \\
0\end{array}$ & 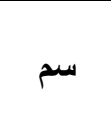 & الطول & \\
\hline $\begin{array}{c}- \\
\cdot, r \otimes q\end{array}$ & $\begin{array}{c}0, \varepsilon \cdot \\
r\end{array}$ & $\neg \cdot, \wedge \bullet$ & 0,7 & 71,074 & كجم & الوزن الو & \\
\hline $\begin{array}{c}- \\
\cdot, \mu r r\end{array}$ & $\begin{array}{c}\cdot, \wedge r \\
\varepsilon\end{array}$ & $1, \wedge \vee 0$ & $\begin{array}{c}, v \cdot \\
v\end{array}$ & $1, v_{0}$ & 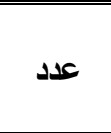 & التوافق "الذراعين & \multirow{7}{*}{ البلنية } \\
\hline$\cdot, I V$ & $\begin{array}{c}1,40 \\
1\end{array}$ & Ir,I ro & $\begin{array}{c}1,01 \\
1\end{array}$ & Ir, ro. & عدد/ث & القوة "عضلات البطن" & \\
\hline $\begin{array}{c}- \\
., 099\end{array}$ & $\begin{array}{c}\cdot, \wedge T \\
\varepsilon\end{array}$ & 0,1 Yo & $\begin{array}{c}\cdot, \wedge r \\
\varepsilon\end{array}$ & $\varepsilon, \wedge \vee \diamond$ & عدد/ث & الرشاقة & \\
\hline$\cdot$, • & $\begin{array}{c}r, \cdot r \\
1\end{array}$ & 01,1 Y & $\begin{array}{c}r, 0 \leq \\
0\end{array}$ & $01,0 \ldots$ & عدد/ث & المرونة "الجذع" & \\
\hline$\cdot, \leqslant \diamond \wedge$ & $\begin{array}{c}7, \& \leqslant \\
7\end{array}$ & r,$\wedge \vee 0$ & Y,,. & $r \cdot, v o$. & 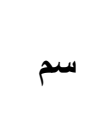 & المرونة "الحوض" & \\
\hline • . & $\begin{array}{c}\cdot, 79 \\
r\end{array}$ & r,q & $\begin{array}{c}\cdot, \wedge \wedge \\
r\end{array}$ & $\varepsilon, \cdot V V$ & عدد/ث & التوازن "الثابت" & \\
\hline $\begin{array}{c}- \\
., 1 \wedge\end{array}$ & $\begin{array}{c}1,01 \\
1\end{array}$ & rr & $\begin{array}{c}1, Y \leq \\
9\end{array}$ & $r_{1}, \wedge \vee_{0}$ & 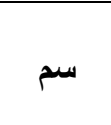 & القدرة العضلية "للرجلين" & \\
\hline
\end{tabular}




\begin{tabular}{|c|c|c|c|c|c|c|c|}
\hline תוד, & $\begin{array}{c}\cdot, Y_{1} \\
q\end{array}$ & עr & $\begin{array}{c}\cdot, 19 \\
r\end{array}$ & $\cdot$, & درجة & وثبة النجمة & \multirow{7}{*}{ المهارية } \\
\hline $\begin{array}{c}- \\
\cdot, \leqslant Y r\end{array}$ & $\cdot, 14$ &.,$\infty 0$ & $\begin{array}{c}\cdot, 1 \wedge \\
\wedge\end{array}$ &., $01 Y$ & 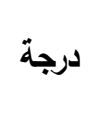 & وثبة الموزة & \\
\hline$\cdot,|v|$ & $\begin{array}{c}\cdot, 17 \\
\wedge\end{array}$ & . & $\begin{array}{c}\cdot, 11 \\
9\end{array}$ & . & 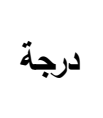 & وثبة الليب & \\
\hline$\cdot, \leqslant 0-$ & $\cdot 1$. & 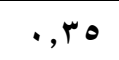 & $\cdot, 11$ & . & درجة & ميزان امامي & \\
\hline$\cdot, 1 r$ & $\cdot, 1 r$ &., $\mathrm{OV}$ & $\cdot, 1$ &., $\mathrm{OV}$ & درجة & ميزان ركبة & \\
\hline$\cdot, 1 r-$ & $\cdot, 11$ &.,$\infty 0$ & $\cdot, 11$ &., 00 & درجة & دوران بتقاطع القدمين & \\
\hline . r. & $\cdot$, Ir & o tra & $\cdot, 1$ & . & درجة & دوران باسية & \\
\hline
\end{tabular}

يتضـح مـن جـدول (r) أن جميـع قيم T المحسـوبة لقياسـات المتغيـرات قيـــ البحـث لأفراد المجموعتين (التجريبية- الضـابطة) قد تراوحت ما بين (- דمب, • :- آ ا , • ) وهذه القيم اقل

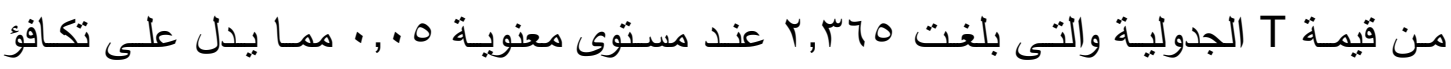
مجموعتى البحث فى تلك المتغيرات. وسنائل وأدوات جمع البيانات اعتمدت الباحثة فى جمع البيانـات والمعلومـات المرتبطة بـالمتغيرات قيد البحث، على الأدوات التالية : (1) الاستمارات والمقابلة الشخصية

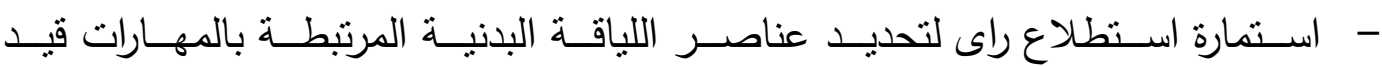

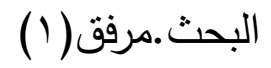
- - استمارة استطلاع راى لتحديد اختبارات اللياقة البدنية المرتبطة بالمهارات قيد البحث. - استمارة لتحديد تمرينات المناسبة للمهارات قيد البحث.مرفق(TABATA القياسات والاختبارات الخاصة بالمتغيرات قيد البحث المتغيرات الأساسيه تم قيـاس المتغيـرات الأساسـيه (السـن - الطـول - الـوزن) لأفـراد مجمـوعتى البحـث (التجريبية -الضابطة) وقد تم تفريغ نتائج القياسات فى الاستمارة المخصصة لذلك. 


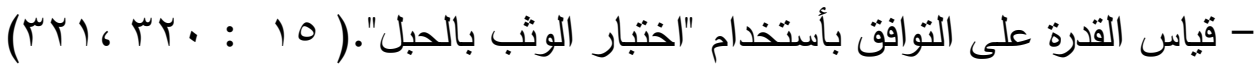

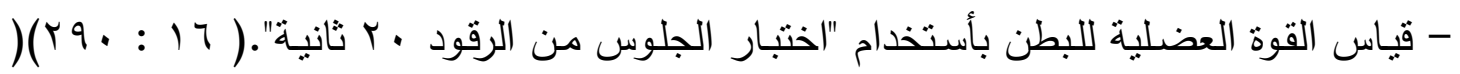
$(Y Y): I Y$

- قياس الرشاقة بأستخدام "اختبار الانبطاح من الوقوف ـ ـ ثوانى".( 11 : 9 ب)

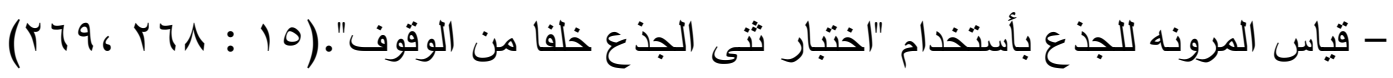

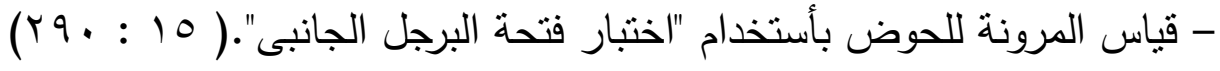

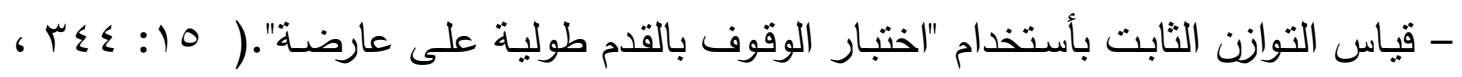

$$
(1 \vee r: 11)(r \leqslant 0
$$

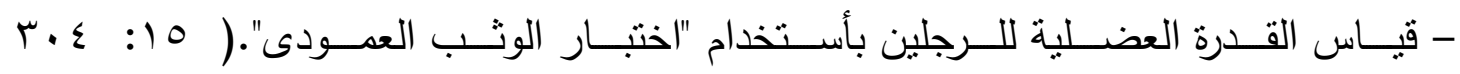

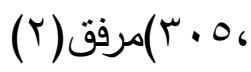

\section{تقييم مستوي الاداء المهاري}

تم التقيم بواسطة لجنـة ثلاثيـة من أعضـاء هيئة تدريس لمقرر التمرينـات بكليـة التربيـة

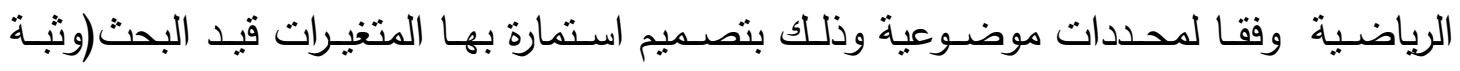

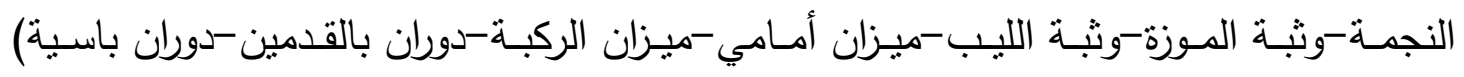

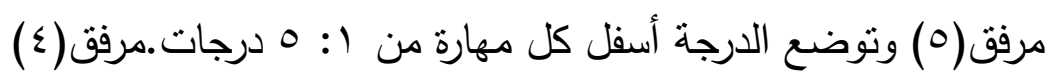


الأجهزة والأدوات

تم اسـتخدام (جهاز ريستاميتز لقيـاس الطسول والوزن/سـم-سـاعة إيقـاف/ ا ـ ث- مسطرة

مدرجة/سم -مراتبأسفنجية).

الاراسات الاستطلاعية

الدراسه الاستطلاعيه الأولى

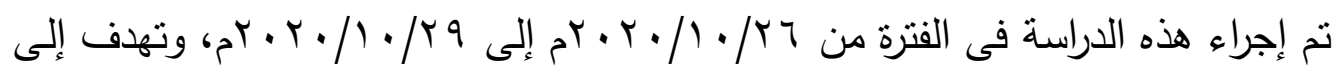

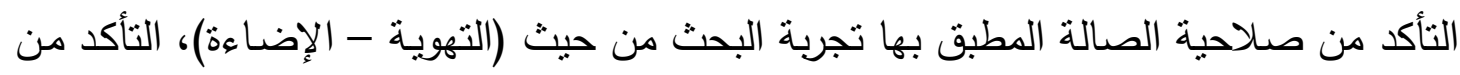

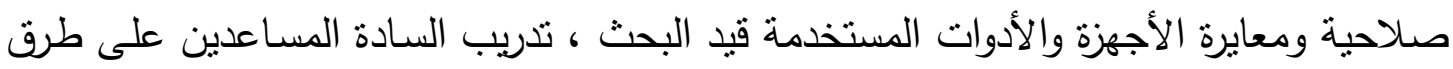
إجراءات الاختبارات قيد البحث وكيفية تدوين النتائج في الاستمارات المعدة لهذا الغرض، وتجربة

تمرينات TABAT المقترحة قيد البحث ومعرفة مدى مناسبتها لطالبات الكلية قبد البحث.

الاراسه الاستطلاعيه الثانية

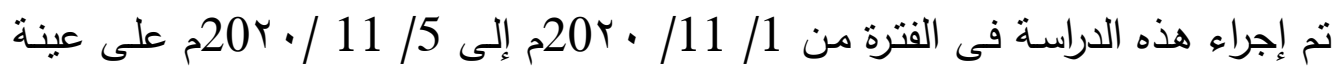

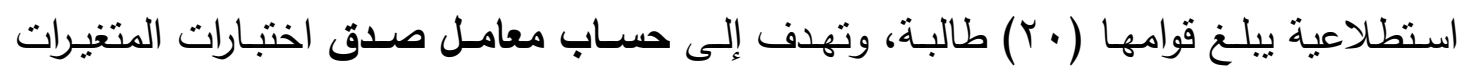
البدنية قيد البحث باستخدام طريقة صدق التمايز ، حيث تم مقارنة قياسات مجموعة من الطالبات المتميزات وقياسات مجموعة اخرى من الطالبات الاقل تميزا، وقد نم إجراء تطبيق الاختبارات

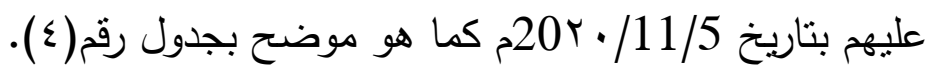

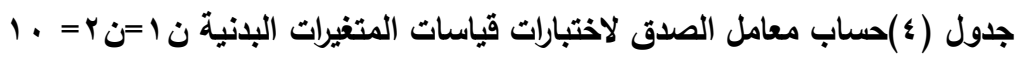

\begin{tabular}{|c|c|c|c|c|c|c|c|c|}
\hline \multirow{2}{*}{ قيمة (ت) } & \multirow{2}{*}{ الفترق بين } & \multicolumn{2}{|c|}{ مجموعة غير مميزة } & \multicolumn{2}{|c|}{ مجموعة مميزة } & \multirow{2}{*}{ القياس } & \multirow{2}{*}{\multicolumn{2}{|c|}{ اختبارات المتغيرات }} \\
\hline & & انحراف & متوسط & انحراف & متوسط & & & \\
\hline *๑, צr & $r, . q$ & $\cdot, \vee \wedge \vee$ & $1, \vee \wedge$ & • & $r, \wedge q$ & عدد & \multicolumn{2}{|c|}{ التوافق الوثب بالحبل } \\
\hline$* q, V \cdot \Lambda$ & $\leqslant, \leqslant \wedge$ & $1, .04$ & ir,. & I,Ar & $10, \leqslant 9$ & عدد/ث & \multicolumn{2}{|c|}{ القوة العضلية رقود . ثت } \\
\hline$* \bullet, \varepsilon r \wedge$ & $r, r$. & $\cdot, \wedge \leq \wedge$ & $\{, \leqslant \wedge$ & $1, \cdot, 1$ & $7, \vee 9$ & عدد/ث & \multicolumn{2}{|c|}{ الانبطاح من الرشاقة } \\
\hline$* \Psi, V \otimes \wedge$ & $\Lambda, r$. & $0, V \backslash \leqslant$ & O., r. & ץ,^५ & $\bullet \wedge, \diamond$. & 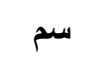 & الجذع & \multirow{2}{*}{ المرونة } \\
\hline$* \varepsilon, \vee q r-$ & $\wedge, \vee \cdot-$ & $0, Y q T$ & Yr, $\{$. & r,YU & Ir,v. & 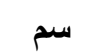 & الحوض & \\
\hline
\end{tabular}

ET०

المجلة العلمية لكلية التربية الرياضية للبنين بالهرم جاععة صلوان

Web : jsbsh.journals.ekb.egＥ-mail : sjournalpess@gmail.com 


\begin{tabular}{|c|c|c|c|c|c|c|c|}
\hline$* \wedge, \& Y Y$ & $0, \ldots r$ & $\cdot, \wedge \leq Y$ & $r, 011$ & $1,7 \vee V$ & $\Lambda, \diamond Y$. & عدد/ث & التوازنالوقوف على \\
\hline$* 1 v, 1,7$ & $\vee, \odot$. & $1, .9$ & $r_{1}, \wedge q$ & $\cdot, \wedge \leq r$ & ץ৭,r^ & عدد & القرة الوثب العمودى \\
\hline
\end{tabular}

يتضح من جدول (ع) أن جميع قيم T المحسوبة للاختبارات البدنية قيد البحث قد نراوحت ما

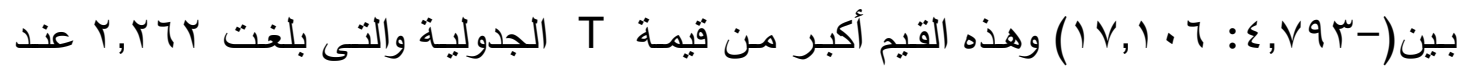
مستوى معنويـة ه ., •، ويثــير ذللك إلى وجـود فروق دالـة إحصـائيا بـين طالبـات المجموعـة المتميزة، وطالبات المجموعة الأقل تميز ، وهذا بدل على صدق الاختبارات قيد البحث فى قياس ما وضعت من أجله. حساب معامل ثبات لاختبارات المتغيرات البدنية باستخدام طريقة تطبيق الاختبار وإعادة تطبيقه Test - Retest الثانى بتاربخ 11/4/ • 20rم بفاصل زمنى مدته ثلاثة أيام كما هو موضح بجدول رقم(0).

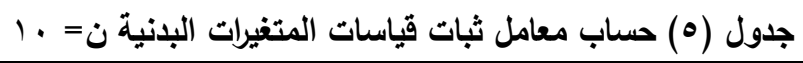

\begin{tabular}{|c|c|c|c|c|c|c|c|c|}
\hline \multirow{2}{*}{ قيمة (ت) } & \multirow{2}{*}{ قيمة (ر) } & \multicolumn{2}{|c|}{ التطبيق الثانى } & \multicolumn{2}{|c|}{ التطبيق الأول } & \multirow{2}{*}{ وحدة } & \multirow{2}{*}{\multicolumn{2}{|c|}{ اختبارات المتغيرات البدنية }} \\
\hline & & انحراف & متوسط & انحراف & متوسط & & & \\
\hline $1, \ldots$ & $*,, \tau \leqslant r$ & •, V & $r$ & $\cdot, T \vee \leqslant$ & $r, 1$ & عدد & \multicolumn{2}{|c|}{ قياس التوافق "الوثب } \\
\hline $1,10 \%-$ & $*,, \wedge \vee r$ & o & 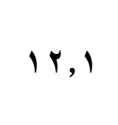 & זדצד, & 11,1 & عدد/ث & \multicolumn{2}{|c|}{ قياس القوة العضلية } \\
\hline ו ו & $*,, q r q$ & .,970 & $\varepsilon, r$ & $1, \cdot 1$. & 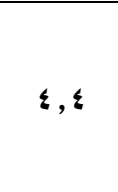 & عدد/ث & \multicolumn{2}{|c|}{ "الانبطاح الرشاقة من } \\
\hline $1, \times 90$ & $*$ *, q 49 & $r, .19$ & $0 ., r$ & $r, 1 \cdot v$ & $0 ., \wedge$ & سم & الجذع & قياس \\
\hline .,rq1- & $* \cdot, \wedge 9 \wedge$ & $r, 090$ & $r 1, r$ & $r, \wedge 9 \wedge$ & $r, 1$ & سم & فتح البرجل & المرونة \\
\hline ., rqu & $*, \wedge \circ r$ & $\cdot, r \leqslant Y$ & $r, \wedge \wedge I$ & $\cdot, \wedge \mid \wedge$ & Y,qY & عدد/ث & \multicolumn{2}{|c|}{ "قالوقوف على العازن الثابتة" } \\
\hline •, & *. , TV. & $1, \cdot v r$ & rY,r & $1, \cdot \Lambda$. & YY, & عدد & \multicolumn{2}{|c|}{ للرجلين"الوثب القدرة العضلية } \\
\hline
\end{tabular}

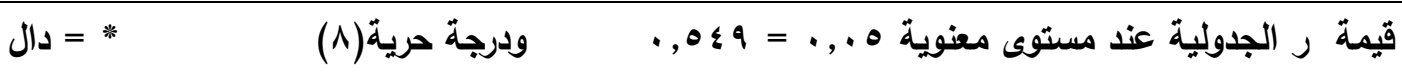

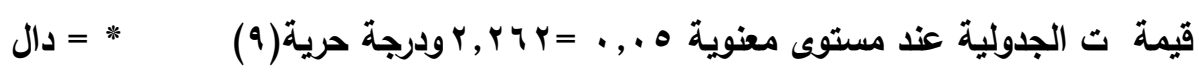
يتضـح مـن جدول (0) أن جميع قيم معـاملات الارتباط المحسوبة لعناصـر اللباقة البدنبـة قيد

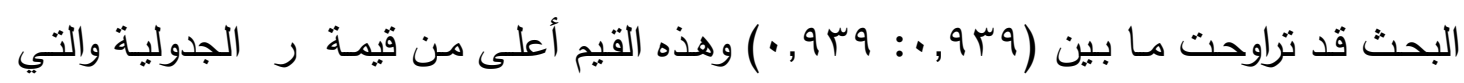
بلغت 9 ؛ , · عند مستوى معنوية 0 . , •، وجميع قيم معاملات اختبار "ت" المحسوبة لاختبارات 


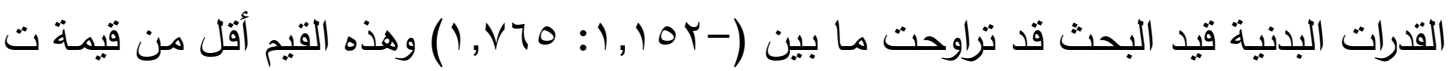

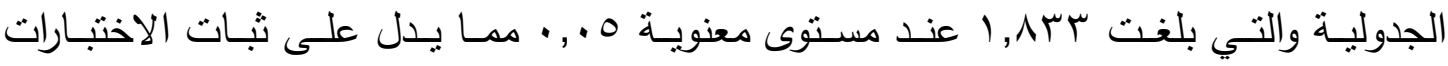
المستخدمة قيد البحث .

هدف البرنامج المقترح لتمرينات TABATA يهدف البرنامج المقترح الي معرفه تاثيره علي مستوي أداء بعض المهارات الاساسية في التمرينات الفنية والصفات البدنية لطالبات كلية التربية الرياضية.

الاسس والقواعد العامة للبرنامج المقترح TABATA -كل تمرين يؤدي لمدة • ب ثانيـة ثم راحة لمدة • ا ثواني ثم يكرر ^ مرات حتي تتنهي من

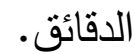
- لا ينصح بأداء التمرين بشكل يومي تمرين يوم واخذ راحة في اليوم الذي يليه. -مراعاة عوامل الامن والسلامة أثناء التدريب. -مراعاة مبدأ التدرج في التمرينات من السهل للصعب ومن البسيط الي المركب. إجراءات تنفيذ التجرية القياسات القبلية

تم إجراء القياسات القبلية للمجموعتين التجريبية والضابطة في جميع المتغرات (البدنية-

$$
\text { التجرية الأساسية) قبد البحث خلال الفترة 11/8،7/ • ب 20م. }
$$

*تم تطبيق البرنامج المتبع بالكلية على المجموعة الضابطة، بينما تم تطبيق برنـامج تمرينات علي المجموعة التجريبيـة مرفق(T) لمدة (T أسـابيع) بواقع ب وحدات تدريبية في الأسبوع أيام (السبت - الاثتين - الأربعاء) ، في الفترة من يوم الاثتين الموافق 11/9/ • r20م

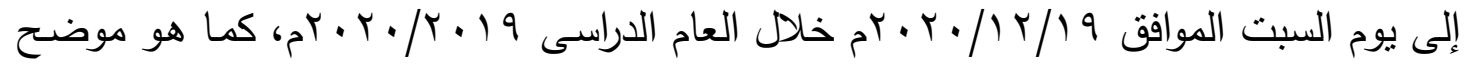

$$
\text { بالتوزيع الزمنى للبرنامج جدول (T). }
$$

\begin{tabular}{|c|c|c|}
\hline التوزيع الزمني للبرنامـج & 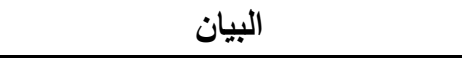 & r \\
\hline ( آ) أسابيع & عدد الأسابيع & 1 \\
\hline ( ) ( ) وحدة تعليمية & عدد الوحدات التعليمية & $r$ \\
\hline (ب) وحدات تعليميه & عدد الوحدات التعليمية في الأسبوع & $r$ \\
\hline ( • ( ) دقيقة & 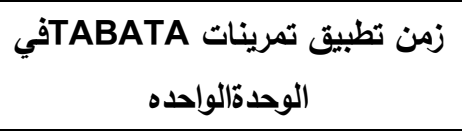 & $\varepsilon$ \\
\hline ) · ( ^ دقيقة & زمن تطبيق تمرينات الاسبيوع & ○ \\
\hline
\end{tabular}

جدول (؟)التوزيع الزمني لبرنامج TABATA المقترح 


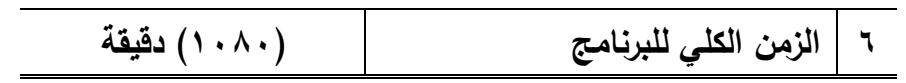

*تم تتفيذ البرنامجين للمجموعتين بحيث جزء الاحماء والجزء المهارى وجزء الختام واحد لكليهما والاختلاف فى الجزء البدنى فقط، حيث تم تتفيذ البرنامج قيد البحث للمجموعة التجريبية، وتم

تتفيذ الوحدة المتبعة للمجموعة الضابطة فقط.

\begin{tabular}{|c|c|c|c|}
\hline المجموعة الضابطة & المجموعة التجريبية & \multicolumn{2}{|c|}{ اجزاء الوحدة } \\
\hline يتم تطبيق جزء الاحماء المتبع بنفس الطريقة & يتم تطبيق جزء الاحماء المتبع بنفس الطريقة & \multicolumn{2}{|c|}{ 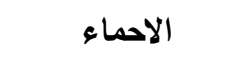 } \\
\hline يتم تنفيذ التمرينات بالبرنامج التقليدى المتبع & يتم تنفيذ تمرينات tabata فى البرنامج المقترح & 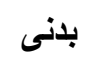 & 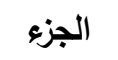 \\
\hline يتم بالاسلوب المتبع & يتم بالاسلوب المتبع & 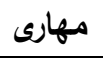 & 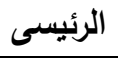 \\
\hline يتم تطبيق جزء الختام المتبع بنفس الطريقة & يتم تطبيق جزء الختام المتبع بنفس الطريقة & \multicolumn{2}{|c|}{ 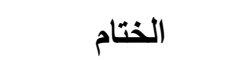 } \\
\hline
\end{tabular}

تم إجـراء القياسـات البعديـة للمجمـوعتين التجريبيـة والضــابطة في جميـع المتغيـرات

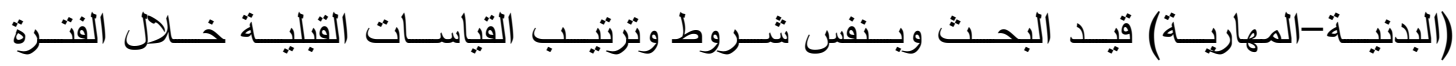

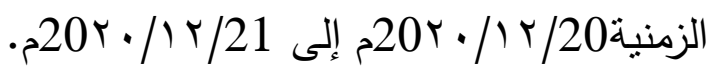

$$
\begin{aligned}
& \text { المعالجات الإحصائية }
\end{aligned}
$$

تـم اسـتخدام البرنـامج الإحصـائى(SPSS) و (EXCEL) للحصـول على المعالجـات

الإحصائية التالية:

(المتوسط الحسابي-الوسيط-الانحراف المعياري -معامل الالتواء-اختبار (T)-معامل الارتباطالنسبة المئوية لمقدار التغير (التحسن).

عرض النتائج ومناقشتها: أولا:عرض النتائج - - مرض نتائج الفرض الأول:

\section{جدول (v)}

دلالة القروق بين متوسط القياسيين (القبلى - البعدى) للمجموعة التجريبية فى

المتغيرات قيد البحث ن=16

\begin{tabular}{|c|c|c|c|c|c|c|}
\hline \multirow{2}{*}{ قيمةت } & \multicolumn{2}{|c|}{ القياس البعدى } & \multicolumn{2}{|c|}{ القياس القبلي } & \multirow{2}{*}{ وحدة القياس } & \multirow{2}{*}{ المتغيرات } \\
\hline & $r \varepsilon \pm$ & س r- & $1 \varepsilon \pm$ & س- & & \\
\hline$* \Lambda, Y \vee$ & $\cdot, \wedge \varepsilon$ & $r, q r$ & $\cdot, V \cdot v$ & $1, \vee 0$. & عدد & التوافق "الذراعين والرجلين" \\
\hline$* \eta, Y \bullet$ & 1,7 & $17, \vee \leqslant$ & $1,0 \wedge 1$ & I Y, YO. & عدد/ث & القوة "عضلات البطن" \\
\hline$* \wedge, 70$ & $1,+r$ & $\mathrm{v}, 1 \mathrm{~V}$ & $\cdot, \wedge r \varepsilon$ & $\varepsilon, \wedge \vee \bullet$ & عدد/ث & الرشاقة \\
\hline$* \square, 7 \varepsilon$ & $\varepsilon, \cdot r$ & 71,00 & $r, 0 \leq 0$ & $01,0 \ldots$ & عدد/ث & المرونة "الجذع" \\
\hline$*$ ๑, ๆ०- & $1, \wedge \varepsilon$ & $1 T, .0$ & Y, & r., vo. & سم & المرونة "الحوض" \\
\hline$* 19, \cdot 1$ & $1,7 v$ & $\Lambda, r_{1}$ & $\cdot, \wedge \wedge r$ & $\varepsilon, \cdot v V$ & عدد/ث & التوازن "الثابت" \\
\hline
\end{tabular}




\begin{tabular}{|c|c|c|c|c|c|c|}
\hline$*$ * & $1, Y \leq$ & $r \cdot, 11$ & $1, r \leq 7$ & r I, Avo & 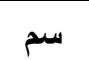 & القدرة العضلية "لارجلين" \\
\hline 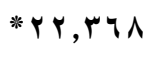 & •,OYK & $\varepsilon, r v o$ &., 194 & $\cdot, 7$ & درجة & وثبة النجمة \\
\hline *Y1,. & . rq. & $\varepsilon, r \wedge v$ &., $1 \wedge \wedge$ &., $01 Y$ & درجة & وثبة الموزة \\
\hline *rr,ror & $\cdot, \leqslant \leqslant \wedge$ & $r, q \wedge \vee$ & $\cdot, 119$ & •, & درجة & وثبة الليب \\
\hline$* Y \leq, \mu \mid \leq$ & $\cdot, 01$ & $r, q \leq$ &., 11 & $\cdot, \mu \varepsilon$ & درجة & ميزان امامي \\
\hline$* r \wedge, Y l$ & $\cdot, r q$ & $\varepsilon, 0$. & $\cdot, 1$ & $\cdot, 0 \mathrm{~V}$ & درجة & ميزان ركبة \\
\hline$* 4, v_{0}$ & $\cdot r \leqslant$ & $\varepsilon, r r$ &., 11 &., 00 & درجة & دوران بتقاطع القدمين \\
\hline$* *_{1, \vee \wedge}$ & $\cdot, 0 \wedge$ & $r, \wedge \vee$ & $\cdot, 1$ & $\cdot, r \varepsilon$ & درجة & دوران باسية \\
\hline
\end{tabular}

يتضح من جدول (V) وشكل ( ( ) وجود فروق دالة إحصائياً بين كل من القياس القبلى والقياس البعدى للمجموعة التجريبية فى المتغيرات قيد البحث لصالح القياس البعدى، حيث أن قيمة ت

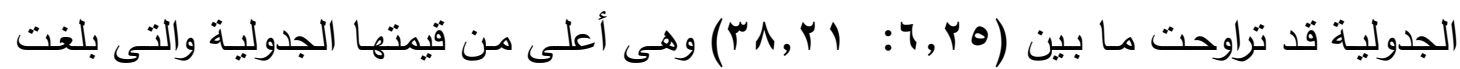

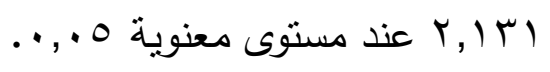

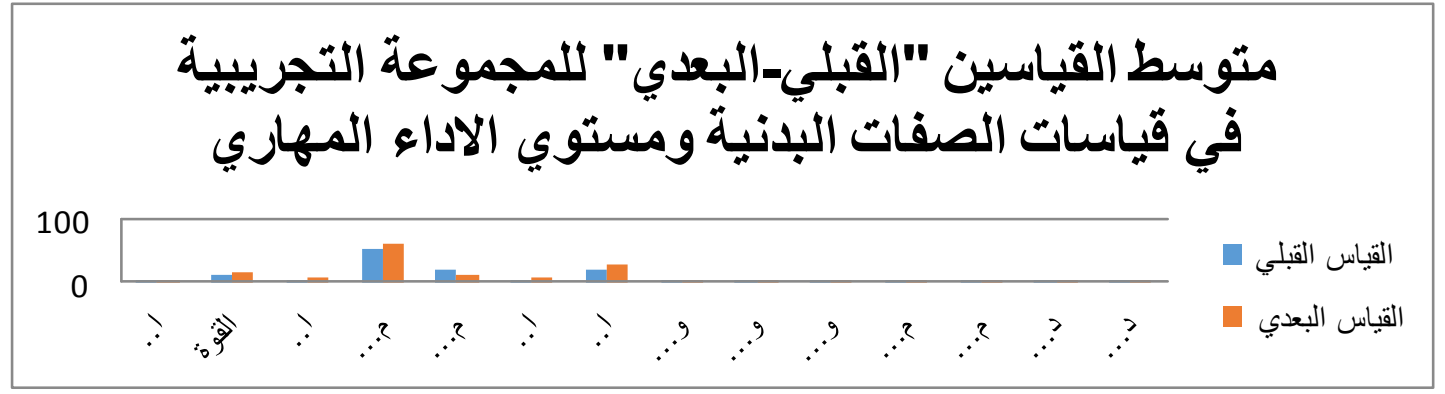

شكل رقم(1) متوسط القياسين "القبلي -البعدي" للمجموعة التجريبية في المتغيرات قيد البحث

جدول (^)

نسب التغير للمجموعة التجريبية فى المتغيرات قيا البحث

$17=\dot{0}$

\begin{tabular}{|c|c|c|c|c|c|}
\hline 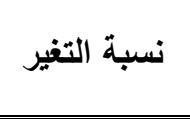 & الفرق بين & متوسط البعدى & متوبط القبلى & وحدة القياس & المتغيرات \\
\hline$\%) r \leq$ & $r, I V-$ & $r, q r$ & $1, \vee 0$. & عدد & التوافق "الذراعين والرجلين" \\
\hline$\% r q, 7 \circ r$ & $\varepsilon, \varepsilon 9-$ & $17, V \leq$ & Ir, ro. & عدد/ث & القوة "عضلات البطن" \\
\hline$\% \leq \vee, \cdot \vee q$ & r, rqQ- & $v, I V$ & $\varepsilon, \wedge \vee 0$ & ع عدد/ث & الرشاقة \\
\hline$\% \backslash \wedge, 0 \leq r$ & $9,00-$ & $71, .0$ & $01,0 \ldots$ & عدد/ث & المرونة "الجذع" \\
\hline$\% r v, 1 \cdot \Lambda$ & $v, v$ & $1 T, 0$ & $r \cdot, v o \cdot$ & 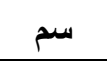 & المرونة "الحوض" \\
\hline$\% 1 \cdot r, \wedge r q$ & $\varepsilon, r m r-$ & $\Lambda, r_{l}$ & $\varepsilon, \cdot v V$ & عدد/ث & التوازن "الثابت" \\
\hline$\% r v, 7 \leq 0$ & $\Lambda, Y \mu \odot-$ & $r \cdot, 11$ & Y I, AV० & 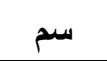 & القدرة العضلية "للرجلين" \\
\hline$\%$ \% & r,vVo & $\varepsilon, \mu \vee 0$ &., 7 & درجة & وثبة النجمة \\
\hline$\% \vee \bullet \neg, \wedge$ & $r, \wedge \vee 0$ & $\varepsilon, r \wedge \vee$ &., $01 r$ & درجة & وثبة الموزة \\
\hline
\end{tabular}




\begin{tabular}{|c|c|c|c|c|c|}
\hline$\% 1 \cdot r q, 1$ & קיוזיק & $r, q \wedge v$ & . r. & درجة & وثبة الليب \\
\hline$\% 1 . \Delta \wedge, \wedge r r$ & $r, q-$ & $r, q \leq$ & צ & درجة & ميزان امامي \\
\hline$\% \curlyvee \wedge ৭, £ \vee r$ & $r, 94-$ & $\varepsilon, 0$ &., $0 \mathrm{~V}$ & درجة & ميزان ركبة \\
\hline$\% \curlyvee \wedge \bullet, \leq ० \leq$ & $r, v \vee-$ & $\varepsilon, r r$ &., 00 & درجة & دوران بتقاطع القدمين \\
\hline$\% 1 \cdot r \wedge$, rro & $r, \Delta r-$ & $r, \wedge v$ & . & درجة & دوران باسبة \\
\hline
\end{tabular}

يتضـح من جدول (^) وشكل (r) أن جميع قياسـات المتغيرات قيد البحث قد تغيرت لدى أفراد

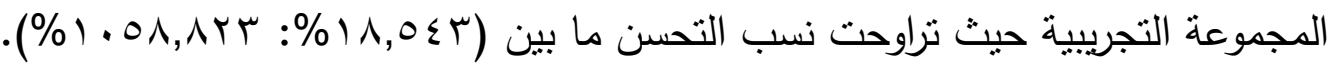

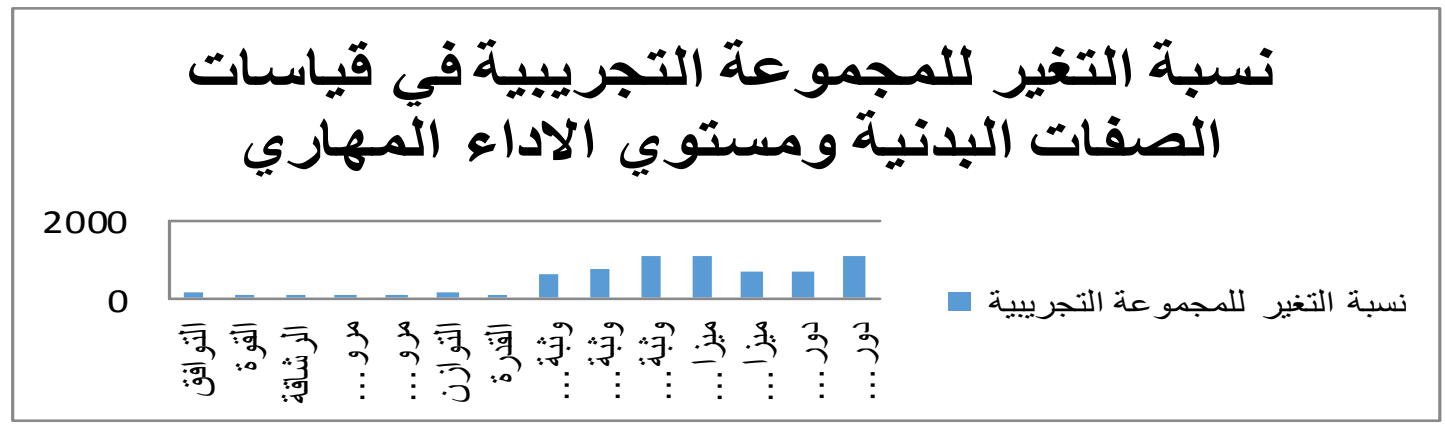

\title{
شكل (r)
}

نسب التغير للمجموعة التجريبية في قياسات المتغيرات قيا البحث - - مرض نتائج الفرض الثاني:

\author{
جدول (9)
}

دلالة الفروق بين متوسط القياسيين (القبلى - البعدى) للمجموعة الضابطة في المتغيرات قيد البحث

$17=\dot{0}$

\begin{tabular}{|c|c|c|c|c|c|c|}
\hline \multirow{2}{*}{ 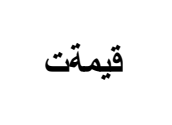 } & \multicolumn{2}{|c|}{ القياس البعدى } & \multicolumn{2}{|c|}{ القياس القبلي } & \multirow{2}{*}{ وحدة } & \multirow{2}{*}{ المتغيرات } \\
\hline & $r \varepsilon \pm$ & س- & $1 \varepsilon \pm$ & س- & & \\
\hline$* \varepsilon, 1 \mu$ & $1, \cdot 1$ & $Y, \wedge \neg$ & •, & $1, \wedge \vee 0$ & عدد & التوافق "الأراعين والرجلين" \\
\hline$* \varepsilon, 7$. & 1,71 & $\mid \leq, 71$ & צ & Ir,IYo & عدد/ث & القوة "عضلات البطن" \\
\hline$* \bullet, 7 \vee$ & $\cdot, v_{1}$ & ד, & •, & 0,1 Yo & عدد/ث & 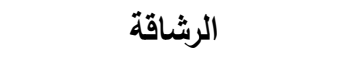 \\
\hline$* 1,9 r$ & $7, Y \varepsilon$ & $\bullet \bullet, \leqslant \wedge$ & $r, \cdot r$ & 01,1 Y & عدد/ث & المرونة "الجذع" \\
\hline$* r, 1 \leq$ & Y,,$\varepsilon$ & 17 & $7, \leq \leq 7$ & rl, $\wedge \vee 0$ & 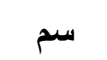 & المرونة "الحوض" \\
\hline$* \wedge, 1 \wedge$ & $1, \varepsilon \varepsilon$ & $\bullet$, i & ., & r,q & عدد/ث & التوازن "الثابت" \\
\hline$* 11, v \leq$ & $1, .9$ & $r \bullet, \wedge$. & 1,011 & rr & 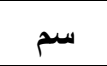 & القدرة العضلية "لارجلين" \\
\hline$* \vee, \diamond ৭ \wedge-$ &., 090 & r, ฯ०. & $\cdot, Y 1 q$ & • , TrV & درجة & وثبة التجمة \\
\hline$* 11, \leq \leqslant Y-$ & $\cdot, \varepsilon \mid r$ & Y, Y Y & $\cdot, 1 \mu$ & $\cdot, 00$ & درجة & وثبة الموزة \\
\hline$* \vee, \varepsilon \neg \varepsilon-$ &., $0 \leq r$ & $r, I \wedge V$ &., 171 & . & درجة & وثبة الليب \\
\hline$* 11$ & .07 & $r, 1$. & $\cdot, 1$ & ه r, & درجة & ميزان امامي \\
\hline
\end{tabular}




\begin{tabular}{|c|c|c|c|c|c|c|}
\hline * $1 \leq, Y \wedge$ &., $0 \leqslant$ & r,Tr & $\cdot$, Ir $^{2}$ & $\cdot, \circ \mathrm{V}$ & درجة & ميزان ركبة \\
\hline * & $\cdot, Y \wedge$ & r.04 & $\cdot, 11$ & $\cdot, 00$ & درجة & دوران بتقاطع القدمين \\
\hline$* 1 \leq,+1$ &.,$\leqslant \wedge$ & $r, 1 \varepsilon$ &., $1 r$ & •, ro & درجة & دوران باسية \\
\hline
\end{tabular}

يتضح من جدول (9) وشكل (r) وجود فروق دالة إحصائياً بين كل من القياس القبلى والقياس البعدى للمجموعة الضـابطة فى المتغيرات قيد البحث لصالح القياس البعدى، حيث أن قيمة ت

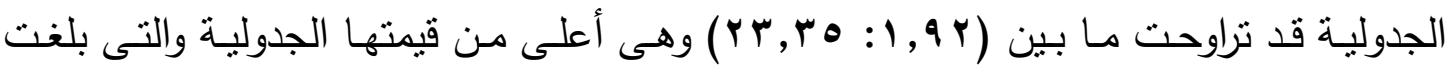

ا آו, Y عند مستوى معنوية 0 ., •.

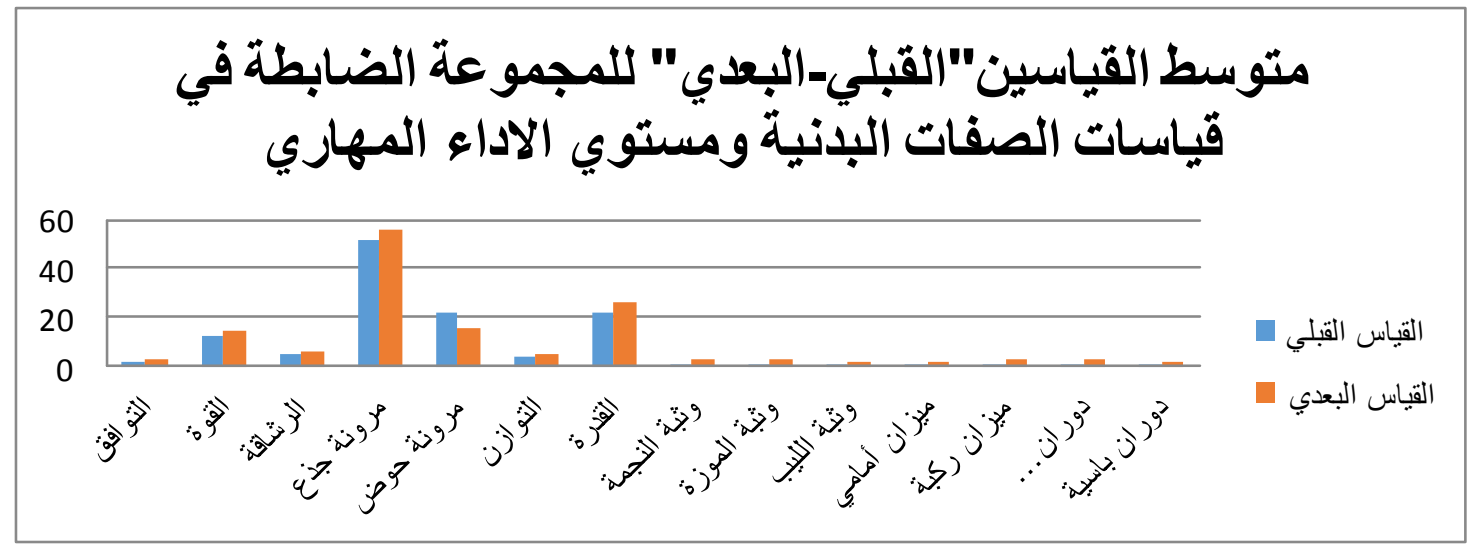

شكل (r) متوسط القياسين"القبلي -البعدي" للمجموعة الضابطة في المتغيرات قيد البحث

جدول (·)

نسب التغير للمجموعة الضابطة في قياسات المتغيرات قيد البحث

\begin{tabular}{|c|c|c|c|c|c|}
\hline نسبة التغير & الفترق بين & متوسط البعدى & متوسط القبلى & وحدة & اسم المهارة \\
\hline$\% \circ r, \circ r$ & $\cdot, 9 \wedge \bullet-$ & $\curlyvee, \wedge \uparrow$ & $1, \wedge \vee 0$ & عدد & التوافق "الذراعين والرجلين" \\
\hline$\% r \cdot, \leq q$ & Y, $\leqslant \wedge \diamond-$ & $\mid \varepsilon, 71$ & Ir,iro & عدد/ث & القوة "عضلات البطن" \\
\hline$\% r \leq, \cdot q$ & $1, r 0-$ & דו, & 0,1 Y & عدد/ث & الرشـاقة \\
\hline$\% \wedge, 01$ & $\varepsilon, r \Delta \Delta-$ & $\diamond \diamond, \leqslant \wedge$ & 01,1 ro & عدد/ث & المرونة "الجذع" \\
\hline \%५ษ,^८- & $\bullet, \wedge \vee \bullet$ & 17 & $r_{1}, \wedge \vee_{0}$ & 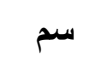 & المرونة "الحوض" \\
\hline$\%$ \%, , ०० & $1, \leqslant 1 Y-$ & •, ט & $r, q r \wedge$ & عدد/ث & التوازن "الثابت" \\
\hline$\% \backslash \vee, r \vee$ & $r, \wedge-$ & $r \bullet, \Lambda$. & rr & 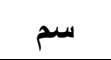 & القرة العضلية "للرجلين" \\
\hline \% & $r, \cdot 1 r$ & r, ז०. & $\cdot, q r v$ & درجة & وثبة النجمة \\
\hline$\% r \wedge \leq$ & $r, 11 r$ & r.ד &., 00. & درجة & وثبة الموزة \\
\hline$\% 0 \leq \wedge, 9$ & 1,10 & $r, I \wedge v$ & $\cdot r r v$ & درجة & وثبة الليب \\
\hline$\% 0 \ldots$ & $1, v 0-$ & $r, 1$. & ט מ, • & & ميزان امامي \\
\hline$\% \diamond \wedge \bullet, \vee 1$ & $r, . Q_{-}$ & r,Tr & $\cdot, 0 \mathrm{~V}$ & درجة & ميزان ركبة \\
\hline$\%$ \% ४ $0, \leqslant 0$ & $r, \cdot 1-$ & r,0 &., 00 & درجة & دوران بتقاطع القدمين \\
\hline
\end{tabular}




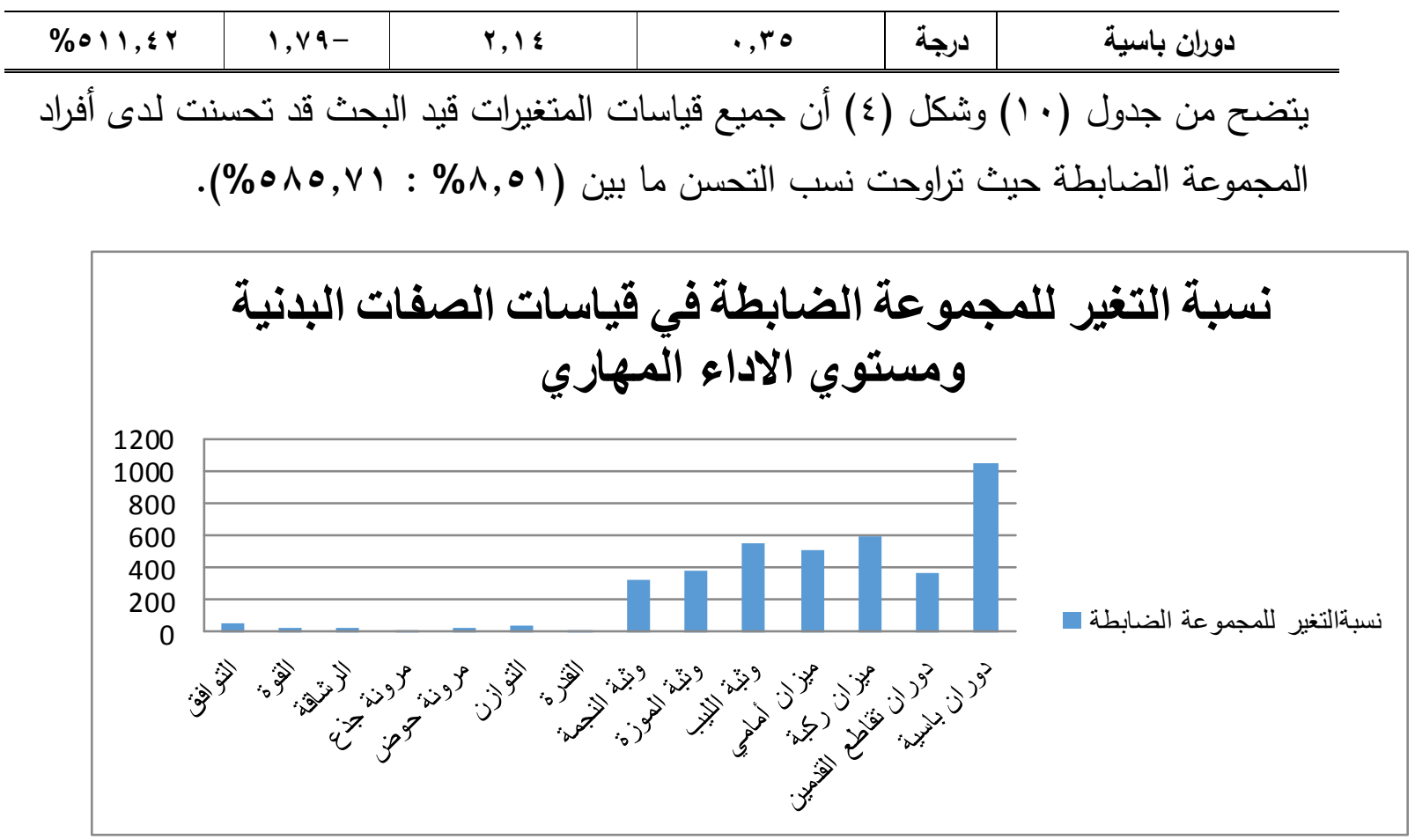

شكل(؛) نسب التغير للمجموعة الضابطة في قياسات المتغيرات قيد البحث

- - عرض نتائج القرض الثالث:

جدول (11) دلالة الفروق بين القياسين البعديين بين المجموعتين (التجريبية - الضابطة)

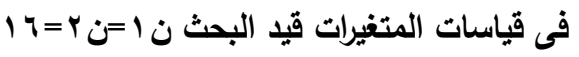

\begin{tabular}{|c|c|c|c|c|c|c|}
\hline \multirow{2}{*}{ قيمةت } & \multicolumn{2}{|c|}{ المجموعة الضابطة } & \multicolumn{2}{|c|}{ المجموعة التجريبية } & \multirow{2}{*}{ وحدة } & \multirow{2}{*}{ 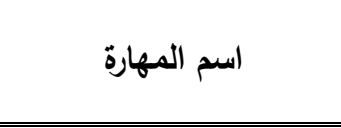 } \\
\hline & $r \varepsilon \pm$ & س- & $1 \varepsilon \pm$ & س- & & \\
\hline$* \Psi, I V$ & $1, \cdot 1$ & $Y, \wedge \uparrow$ & $\cdot, \wedge \varepsilon$ & r,qr & عدد & التوافق "الذراعين والرجلين" \\
\hline$* \mu, v$. & 1,71 & $1 \leq, 71$ & 1,7 & $17, \vee \leqslant \varepsilon$ & عدد/ث & القوة "عضلات البطن" \\
\hline$* Y, 0 \leq$ & $\cdot, v_{1}$ & q & $1, \cdot r$ & $v, 1 v$ & عدد/ث & الرشاقة \\
\hline$* \uparrow, १ \vee$ & $7, Y \leq$ & $00, \leqslant \wedge$ & $\varepsilon, \cdot r$ & 71,0 & عدد/ث & المرونة "الجذع" \\
\hline$* \varepsilon, \wedge \bullet-$ & $Y,\rceil \leq$ & 17 & $1, \wedge \varepsilon$ & $1 \mathrm{r}, 0$ & 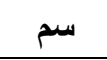 & المرونة "الحوض" \\
\hline$* \bullet, r r$ & $1, \leq \varepsilon$ & $\bullet, \mu_{0}$ & $1,7 v$ & $\Lambda, r_{1}$ & عدد/ث & التوازن "الثابت" \\
\hline$* 1 \cdot, r V$ & $1, \cdot 9$ & $r \bullet, \Lambda$. & $1, r \leq$ & $r \cdot, 11$ & 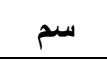 & القدرة العضلية "للرجلين" \\
\hline$* \eta, 10 \mathrm{~V}$ &., 090 & Y, ๆ०. & $\cdot$, orr & $\varepsilon, \mu \vee 0$ & درجة & وثبة النجمة \\
\hline$* \wedge, \diamond \vee \mu$ & $\cdot, \varepsilon 1 \Gamma$ & $r, 79 r$ & $\cdot, r q$. & $\varepsilon, \Gamma \wedge V$ & درجة & وثبة الموزة \\
\hline$* V, Y r r$ & $\cdot, 0 \leq r$ & $r, 1 \wedge V$ & $\cdot, \leqslant \leqslant \wedge$ & $r, q \wedge V$ & درجة & وثبة الليب \\
\hline$* \wedge, 91$ &., 07 & $r, 1$. & $\cdot, \diamond \wedge$ & $r, q \leq$ & درجة & ميزان أمامي \\
\hline$* 1 \cdot, \wedge \varepsilon$ & $\cdot, 0 \leq$ & $r, 7 r$ & $\cdot, r q$ & $\varepsilon, 0$ & درجة & ميزان ركبة \\
\hline$* 10, . \varepsilon$ & $\cdot, r \wedge$ & $r, 07$ & $\cdot, r \varepsilon$ & $\varepsilon, r r$ & درجة & دوران بتقاطع القدمين \\
\hline$* \wedge, 90$ & $\cdot, \varepsilon \wedge$ & $Y, I \varepsilon$ & $\cdot, \diamond \wedge$ & $r, \wedge v$ & درجة & دوران باسية \\
\hline
\end{tabular}


يتضـح مـن جدول (1) وشـكل (0) وجـود فـروق دالـة إحصـائياً بين القياسـين البعديين بـين المجموعتين التجريبية والضـابطة فى قياسات المتغيرات قيد البحث لصالح المجموعة التجريبية،

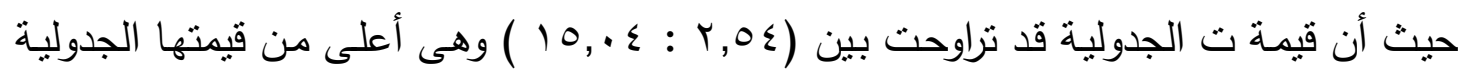

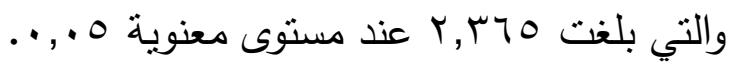

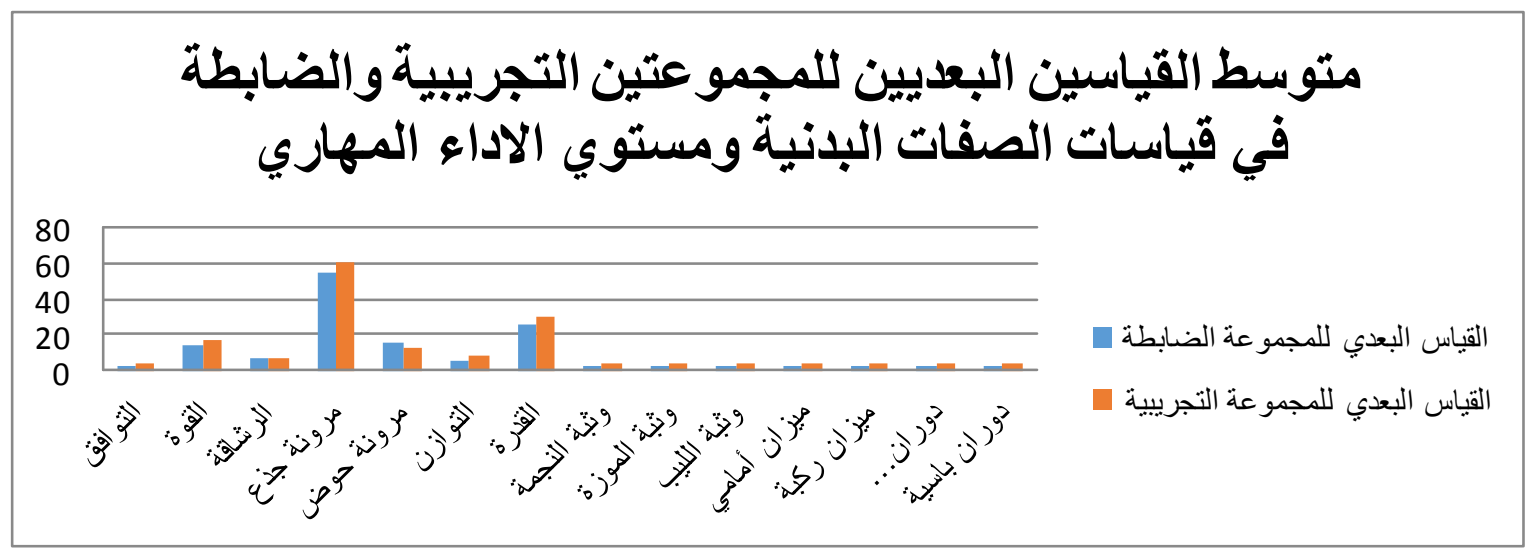

شكل(0) متوسط القياسين البعديين للمجموعتين التجريبية والضابطة في قياسات المتغيرات

\section{قيد البحث}

جدول (Y I ) مقارنة نسب التغير فى المتغيرات

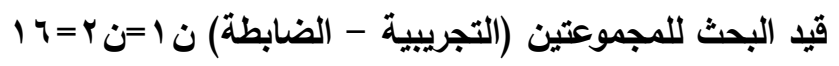

\begin{tabular}{|c|c|c|c|c|c|c|c|c|}
\hline \multirow[b]{2}{*}{ فرق نسبه } & \multicolumn{3}{|c|}{ المجموعة الضابطة } & \multicolumn{3}{|c|}{ المجموعة التجريبية } & \multirow[b]{2}{*}{ وحدة القياس } & \multirow[b]{2}{*}{ المهارات } \\
\hline & نسبة التغير & مثوبط & مثوبط & التغبة & مثوبط & متوسط & & \\
\hline$\% \vee 1, \varepsilon \vee$ & $\% \circ r, \circ r$ & Ү,^ & $1, \wedge \vee 0$ & $\% 1$ Y & r, qr & $1, \vee \bullet$ & 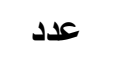 & التوافق "الذراعين والرجلين" \\
\hline \%17, 1 & $\% r \cdot, \varepsilon q$ & $\mid \varepsilon, 71$ & Ir,I ro & $\%$ \%, т०r & $17, V \varepsilon$ & Ir, ro. & عدد/ث & القوة "عضلات البطن" \\
\hline 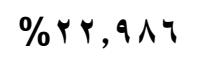 & $\%<\varepsilon, .9$ & qu & 0,1 Y & $\% \leq \vee, \cdot \vee q$ & $\mathrm{~V}, \mathrm{IV}$ & $\varepsilon, \wedge \vee \diamond$ & عدد/ث & الرشاقة \\
\hline \%1 • מ & $\% \wedge, 01$ & $\bullet \bullet, \leqslant \Lambda$ & 01,1 Yo & $\% \backslash \wedge, \diamond \leq \Psi$ & 71,0 & $01,0 \ldots$ & عدد/ث & المرونة "الجذع" \\
\hline$\% 1 \cdot, r \circ \Lambda$ & $\%$ \% ४,^०- & 17 & rl, $1 \vee 0$ & $\% r v, 1 \cdot \Lambda$ & $1 \%, 0$ & $r \cdot, V \bullet \cdot$ & سم & المرونة "الحوض" \\
\hline$\% 7 \vee, 9 \vee 1$ & $\%$ \% , ^०० & $\bullet, \mu_{0}$ & $r, q \mu \wedge$ & $\% 1 \cdot r, \wedge r q$ & $\Lambda, \mu_{l}$ & $\varepsilon, \cdot v V$ & عدد/ث & التوازن "الثابت" \\
\hline$\% r \cdot, r v o$ & $\% \backslash \vee, r \vee$ & $r \bullet, \Lambda$. & $r r$ & $\% r v,\urcorner \leq 0$ & $r \cdot, 1$ & Y I, AV० & 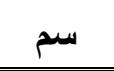 & القدرة العضلية "للرجلين" \\
\hline \%r, & \% & Y, Ү०. & ., & $\%$ \% & $\varepsilon, \mu \vee v$ &., 7. & درجة & وثبة النجمة \\
\hline$\% r \vee r, \Lambda$ & $\%$ \% & $r, 77 r$ &,,$\infty \bullet$ & $\% \vee \bullet ч, \wedge$ & $\varepsilon, \Psi \wedge V$ &., $01 r$ & درجة & وثبة الموزة \\
\hline$\% \leq q \cdot, r$ & $\% \circ \leq \wedge, q$ & $r, I \wedge V$ & • & $\% 1 \cdot r q, 1$ & $r, q \wedge V$ & $\bullet$, & درجة & وثبة الليب \\
\hline$\% \diamond \diamond \wedge, \wedge r r$ & $\% 0 \ldots$ & $r, 1$ & $\bullet$ & 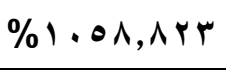 & r, q & $\cdot, r \varepsilon$ & درجة & ميزان امامي \\
\hline \% & $\% \circ \wedge \bullet, \vee 1$ & $r, 7 r$ & $\cdot, \circ V$ & $\% \curlyvee \wedge q, \varepsilon \vee r$ & $\varepsilon, 0$ & $\bullet, \circ V$ & درجة & ميزان ركبة \\
\hline$\% r r \cdot, \cdot \varepsilon$ & $\%$ \% & Y,० &, 00 & $\% \curlyvee \wedge 0, \varepsilon 0 \varepsilon$ & $\varepsilon, \mu r$ &, 00 & درجة & دوران بتقاطع القدمين \\
\hline
\end{tabular}




\begin{tabular}{|c|c|c|c|c|c|c|c|c|}
\hline$\% \circ$ \% $^{\prime}, \wedge 10$ & $\% 011, \varepsilon r$ & $r, 1 \leq$ & ס ט, • & $\% 1 \cdot r \wedge, r{ }^{\prime}$ & $r, \wedge v$ & ـ & درجة & دوران باسية \\
\hline
\end{tabular}

يتضح من جدول (Y ( ) وشكل(T) نسب التغير بين القياسين القبلبوالبعدى للمجموعتين التجريبية والضـابطة فى قياسـات المتغيـرات قيد البحث كمـا يتضـح وجـود فروق فى نسـب التغير بـين المجموعـة التجربيــة والمجموعـة الضـابطة فبالصـفات البدنيـة ومستويات الأداء المهارى حيث

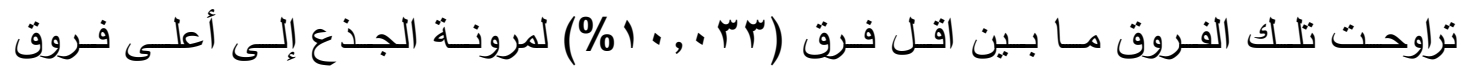

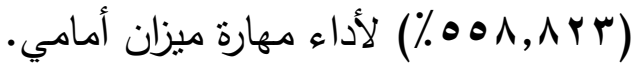

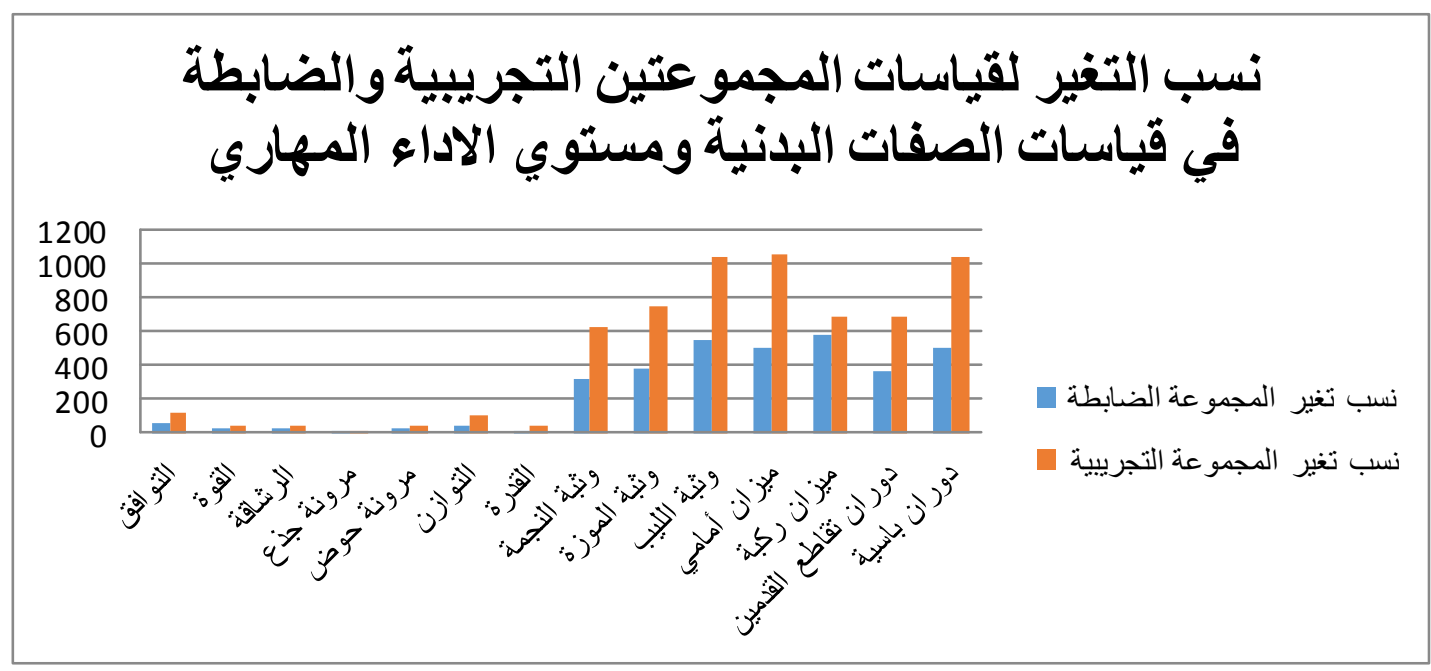

شكل(؟) نسب التغير لقياسات المجموعتين التجريبية والضابطة في قياسات المتغيرات قيد البحث

\section{مناقشة النتائج}

قامتالباحثة بعرض نتائج التحليل الإحصائى لبيانات البحث الخاصة بكل مجموعة من المجموعتين (التجريبية - الضـابطة) على حدة، وذلك لمعرفة دلالات الفروق بين القياس القبلى والبعدى في قياسات المتغيرات البدنية ومستوي الأداء المهارى (قيد البحث): مناقشة نتائج الفرض الاول: يتضـح مـن جدول (V) وشـل ( (l)وجـود فروق دالـة إحصـائياً بين متوسـ القياسـيين (القبلى - البعدى) للمجموعة التجريبية فى قياسات المتغيرات البدنية (توافق الذراعين والرجلين-قوة عضلات البطن-الرشاقة-مرونة الجذع-مرونة الحوض-التوازن الثابت-القدرة العضلية للرجلين) ومستوي الأداء المهارى للمهارات قيد البحث (وثبـة النجمـة- وثبـة الموزة- وثبـة الليب-ميزان أمامي -ميزان ركبة-دوران بتقاطع القدمين -دوران باسية) لصالح القياس البعدى، حيث أن قيمة

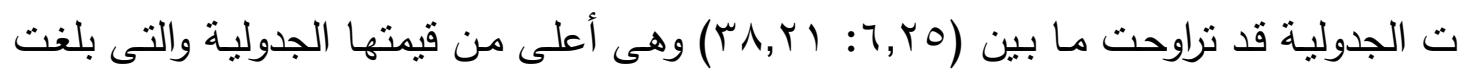
آו, Y عند مستوى معنوية 0 .,... كما يوضـح جدول (^) وشكل (Y) أن جميع قياسـات المتغيرات البدنية و مستوي الأداء 
المهارى قيد البحث قد تحسنت لدى طالبات المجموعة التجريبية، حيث كانت أعلى نسبة تحسن

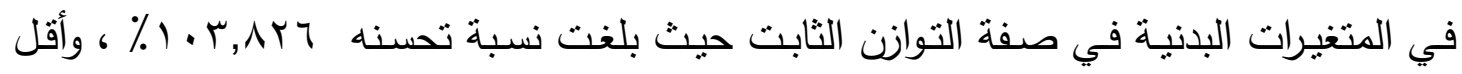

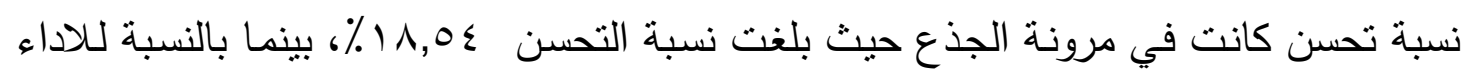

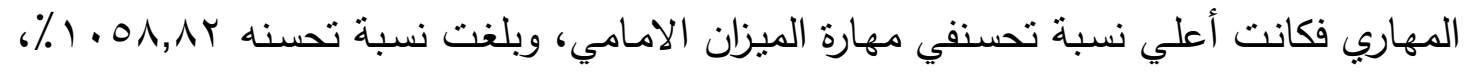

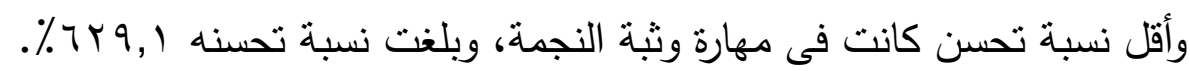
ويعزى الباحثة الفروق الدالة إحصائياً، ونسب التحسن الحادثة لدى طالبات المجموعة التجربيية في المتغيرات البدنية ومستوي الأداء المهارى قيد البحث إلى التأثير الإيجابى لبرنامج تمرينات TABATAالمقترح، مما عمل علي تتمية عناصر اللياقة البدنية (التوافق والقدرة والرشاقة والمرونـة والتـوازن والقـوة)، والتـى بـدورها سـاعدت فـى رفـع مسـتوى الاداء المهـارى للطالبـات فى(الوثبات -التوازنات-الدورانات) قيد البحث. كما ترجعالباحثة هذا التطور إلى تأثير برنامج تمرينات TABAT قيد البحث، والذى ساعد على رفع مستوى عناصر اللياقة البدنية لدى طالبات المجموعة التجريبية والذى بدورة ادى الى رفـع مسـتوى اداء الوثبـات-التوازنـات-الدورانات لـدى هؤلاء الطالبـات، مـع مراعـاة تقنين البرنامج طبقا لنوع التمرينات.

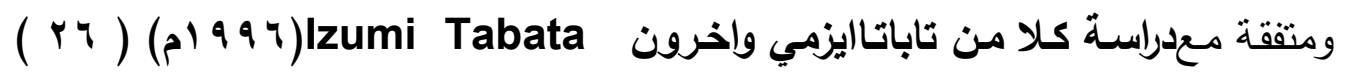

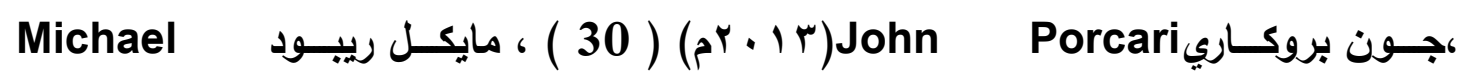
، J.Rebold

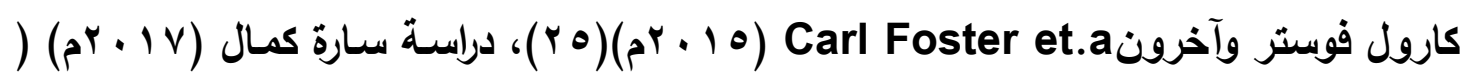

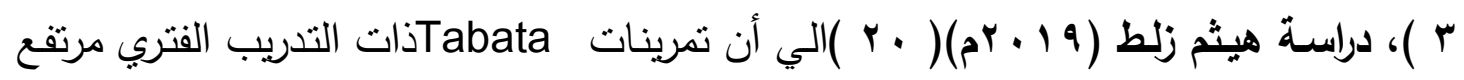
الثدة لها تأثير ايجابي تحسين وتطوير القدرات البدنية المختلفة وتدل نتائجهم علي وجود فروق بين القياسين القبلي والبعدي للمجموعة التجريبية لصالح القياس البعدي. وبذلك فنتائج الدراسة بجدولى رقم (V)،(^) تحقق صحة الفرض الاول والذى ينص على:توجد فروق دالة إحصائياً بين القياسين القبلى والبعدى للمجموعة التجربيية فى مستوي اللياقة البدنية ومستوي الاداء المهاري قبد البحث لصالح القياس البعدى. مناقشة نتائج الفرض الثاني: يتضـح مـن جدول (9) وشكل (ب) وجود فروق دالـة إحصـائياً بين منوسط القياسيبين (القبلى - البعدى) للمجموعـة الضـابطة فى قياسـات المتغيرات البدنيـة (التوافق والقدرة والرشـاقة والمرونة والتوازن والقوة)ومستوي الأداء المهارى للمهارات قيد البحث (وثبة النجمة- وثبة الموزةوثبـة الليبـ-ميـزان امـامي-ميززان ركبـة-دوران بتقـاطع القدمين -دوران باسـية) لصـالح القيـاس 


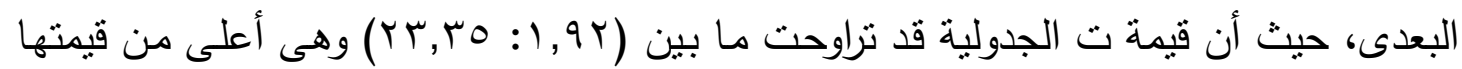

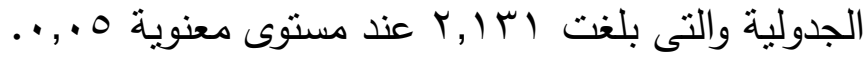

وكما يوضتح جدول (· ( ) وشكل (ع) أن جميع قياسات المتغيرات البدنية ومستوي الأداء المهارى قيد البحث قد تحسنت لاى طالبات المجموعة الضابطة، حيث كانت أعلى نسبة تحسن في المتغيرات البدنية في صفة التوافق حيث بلغت نسبة التحسن هor,or\% وأقل نسبة تحسن

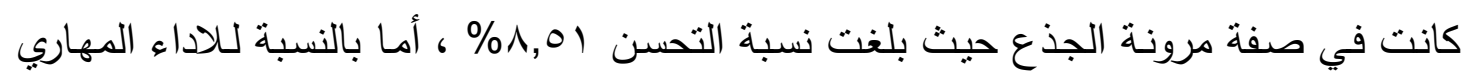

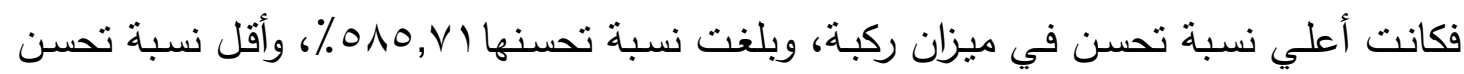
كانت فى وثبة النجمة، وبلغت نسبة تحسنها 7 ابـ\%. ويشير محمد حسن عـلاوى ب 99 امإلى أن التدريب يسعى إلى تتمية وتطوير اللياقة

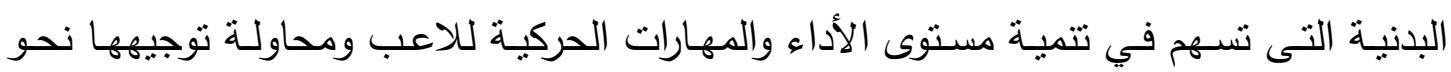

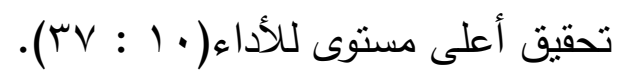
وتعزو الباحثة أن التأثير الإيجابى الذى حدث فى مستوى أداءات المجموعة الضـابطة كان السبب فيه استمرارية وانتظام المجموعة الضابطة داخل البرنامج التدريبى، الأمر الذى أدى إلى حدوث التكيف فى التدريب وبالتالى ارتفاع مستوى الأداء البدنى والمهارى.

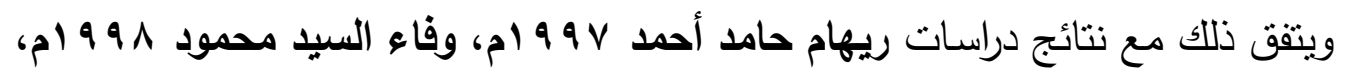

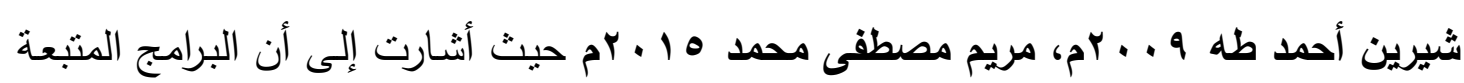
والمطبقة على أفراد المجموعة الضابطة لها تأثثر إيجابى على تحسن الكفاءة البدنية ومستوى

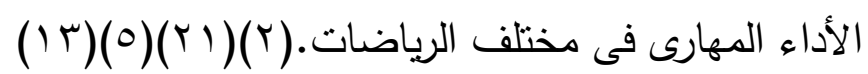
كما يتفق ذللك مع نتائج دراسات شيرين احمد طة ه . . Yم، هبة محمد سعيد ؛ . . Y م، هالة حمد سعيد 999 ام، نجوى سليمان بيومى \& 99 (م، الى البرامج التذربيية للتمرينات تعمل على رفع الكفاءة البدنية وبدورة رفع مستوى الاداءالمهاريفى التمرينات الفنية الايقاعية. (0) (9 ( ) $(1 \vee)(1 \wedge)$ وتقسر الباحثة سبب تقدم طالبات المجموعة الضابطة فى مستويات القياس البعدى عن القبلفيالصفات البدنيـة ومستوى الاداءالمهاري قيد البحث إلى تأثير البرنامج التدربيـالتقليدى، وبذلك يكون مقدار التحسن الحادث بين المجموعتين فى نتائج القياس البعدى هو القيصل لتحديد تقدم المستوى ولصالح المجموعة التجريبية لتأثير البرنامج المقترح تمرينات ومما تقدم تكون صحة الفرض الثانى للبحث قد تحقق والذى ينص على توجد فروق دالة إحصـائياً بـين القياسـين القبلى والبعدى للمجموعـة الضـابطة فـى المتغيـرات البدنيـة و مسـتوي الاداءالمهاري فى التمرينات الفنية قيد البحث لصالح القياس البعدى. 
مناقشة نتائج الفرض الثالث :

ويتضح من جدول (1) (1) والثكل (0) وجود فروق دالة إحصائياً بين منوسط القياسيين البعديين بين للمجموعة الضـابطة والمجموعة التجريبية في قياسـات المتغيرات البدنية(التوافق

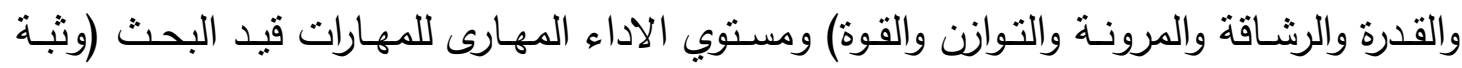
النجمة-وثبة الموزة- وثبة الليب-ميزان امامي-ميزان ركبة-دوران بتقاطع القدمين-دوران باسية)

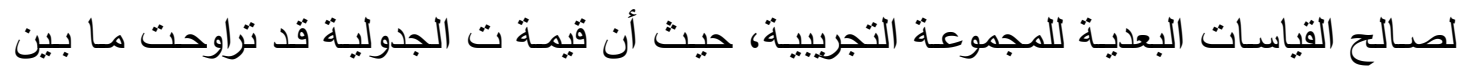

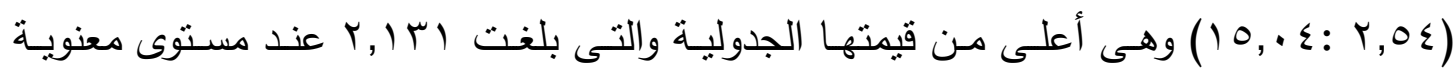
$\cdot \cdot, \cdot 0$

كما يوضح جدول (r () وشكل (T) أن جميع قياسات المتغيرات البدنية ومستوي الأداء المهارى قبد البحث قد تحسنت لدى طالبات المجموعة التجريبية وطالبات الجموعة الضابطة، حيث كانت أعلى نسبة لفروق نسب التحسن بين المجموعتين فمهارة ميزان أمامي، وبلغ فرق

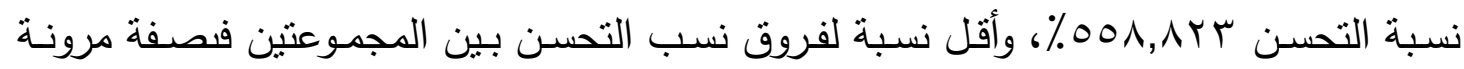

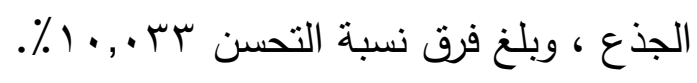

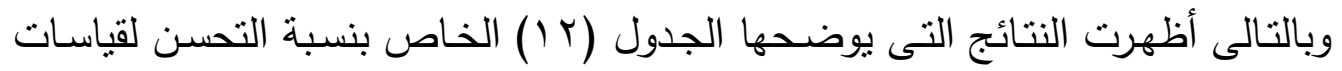

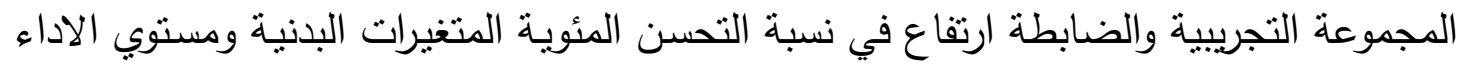
المهاري للمجموعة التجريبية أفضل من نسبة التحسن المئوية للمجموعة الضابطة. وتعزوالباحثـة ذلـك التحسـن لمستوى أداء المجموعـة التجريبيـة فـى المتغيـرات البدنيـة

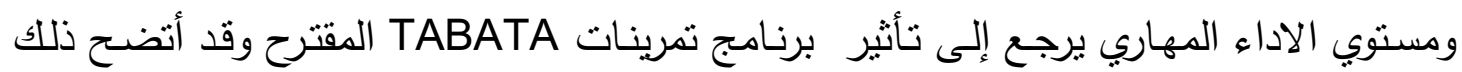

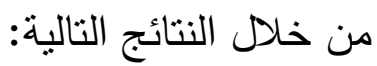
صفة التوافق وصلت نسبة التحسن في المجموعة التجريبية ع ب ا ب بينما في المجموعة

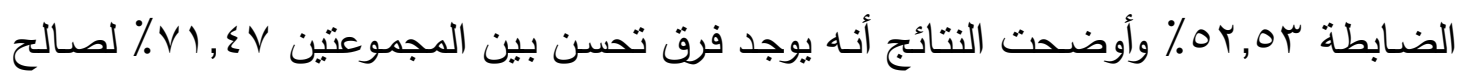

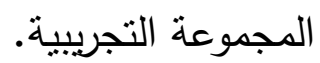

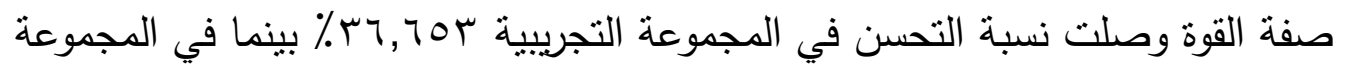

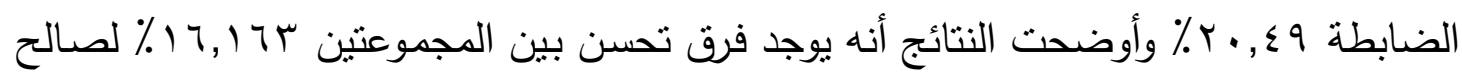

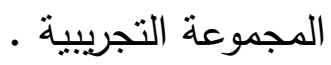

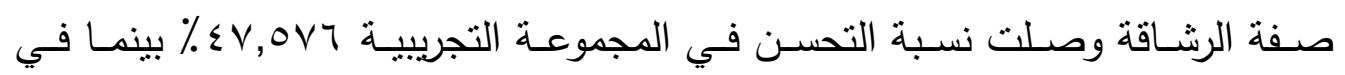

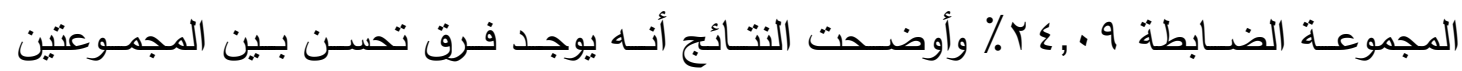

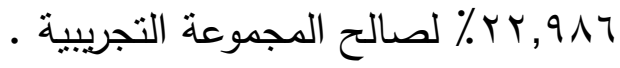

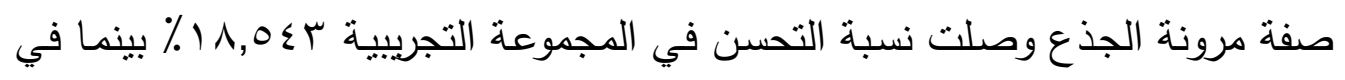




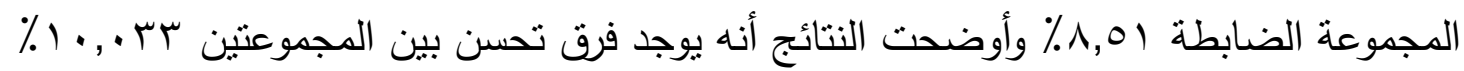
لصالح المجموعة التجريبية .

صفة مرونة الحوض وصلت نسبة التحسن في المجموعة التجربيية م • ـ

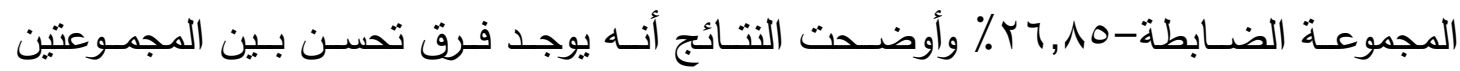

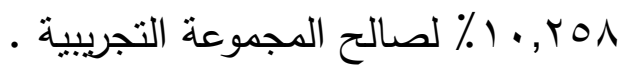
صفة التوازن الثابت وصلت نسبة التحسن في المجموعة التجريبية جبر, ـ ـ ( بينما في المجموعة الضـابطة 00,00ر٪\% وأوضـحت النتائج أنـه يوجد فرق تحسن بين المجموعتين . . الصالح المجموعة التجريبية

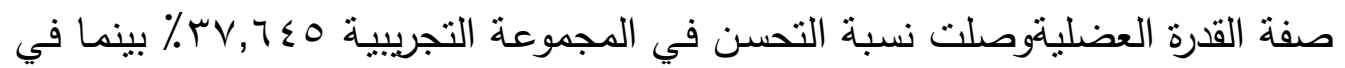

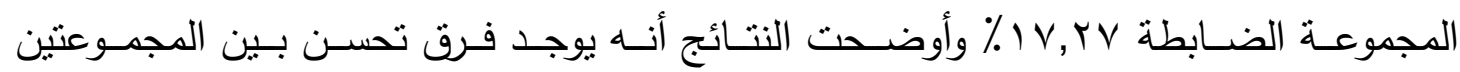

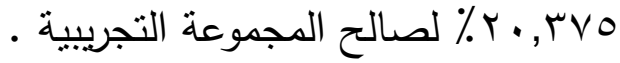

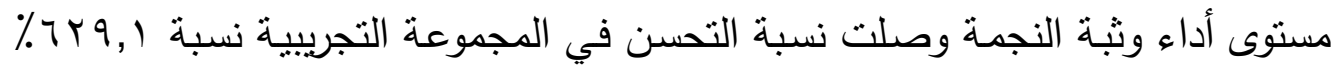
بينما في المجموعة الضابطة جاس ٪ وأوضحت النتائج أنه يوجد فرق تحسن بين المجموعتين 1, ا 1 \% لصالح المجموعة التجريبية.

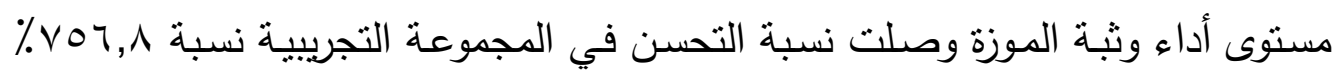

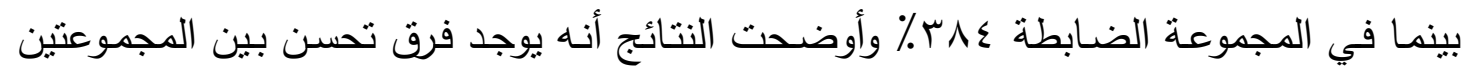
(

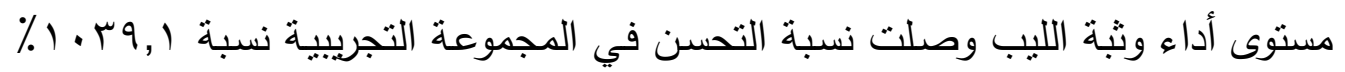

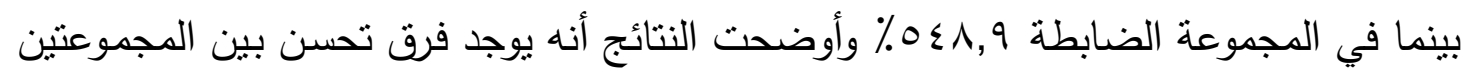

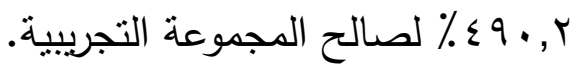
مسـتوى أداء ميـزان أمـامي وصـلت نسـبة التحسـن فـي المجموعـة التجريبــة نسـبة

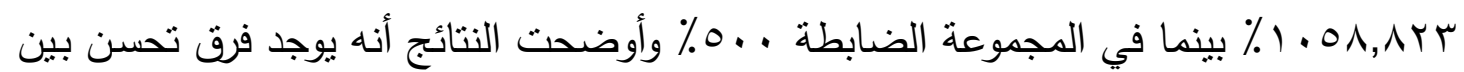

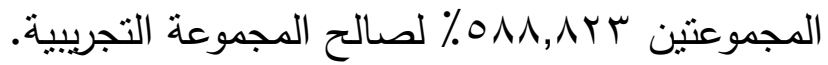

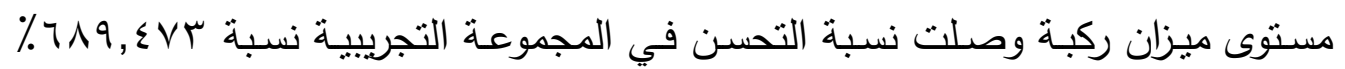

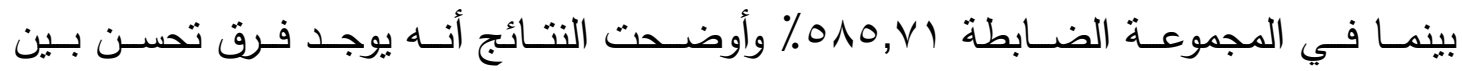
المجموعتين سج, r • 1 \% لصالح المجموعة التجريبية. مستوى أداء دوان تقاطع القدمين وصلت نسبة التحسن في المجموعـة التجريبيـة نسبة

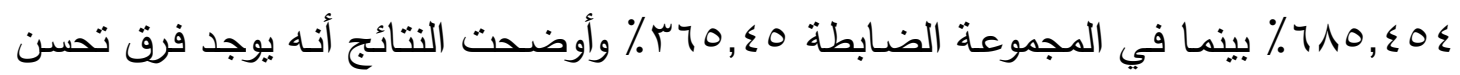
بين المجموعتين ع . ., . بr \% لصالح المجموعة التجربيية. 
مسـتوى أداء دوران باسيةوصـلت نسـبة التحسـن فـي المجموعـة التجريبيــة نســبة

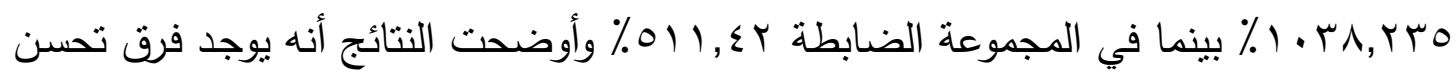

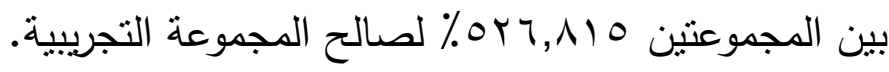
وترجـع الباحثـة سـبب التحسـن الحـادث فـى المجموعـة التجريبيـة مقارنـة بالمجموعـة الضابطة فى قياسات المتغيرات البدنية ومستويات الأداء المهارى (قيد البحث) إلى أن البرنامج التدريبى باسـتخدام تمرينـات TABATA أثثر تـأثنر ا فعـالا على تلك المتغيـرات حيـث أن التذريبات البدنية المستخدمة TABATA قيد البحث قد ساهمت فى إتقان وتحسين مستوى الأداء المهارى للمهارات قيد البحث، حيث راعى برنامج تمرينات TABATA التتوع من حيث البناء الديناميكى وتـأثير هـ على العضـاتلات العاملـة فـى اداء الوثبـات -التوازنـات -الـدورانات وتتميـة عناصر اللياقة البدنية الخاصة بتلك المهارات، وهذا لم يتوفر لطالبات المجموعة الضـابطة والتى اعتمدت على التدربيات التقليدية.

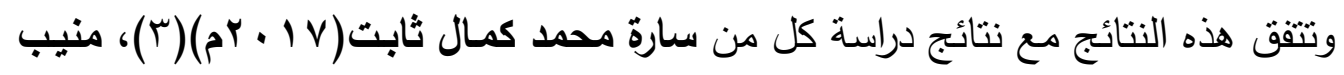

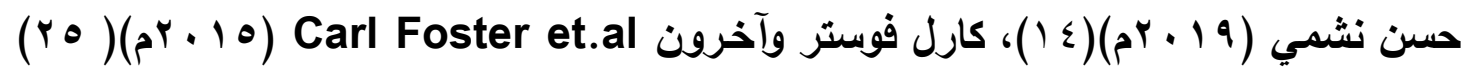
علي أن تمرينات تاباتاTabata ادت الي تحسين القدرات البدنية ومستوي الاداء المهاري . ومن خلا النتائج السابقة يكون قد تحقق صحة الفرض الثالث والذى ينص على توجد فروق دالة إحصائيا بين المجموعة التجربيية والمجموعة الضابطة فى المتغيرات البدنية و مستوى الاداءالمهاري فى التمرينات الفنية قيد البحث لصالح القياس البعدى للمجموعة التجربيية. الاستخلاصات والتوصيات: الاستخلاصات : فى حدود هذة الدراسـة واسترشـادا باهدافها والخطوات المتبعـة فيها للتحقق من صـحة الفروض وفى ضوء القياسات المستخدمة وفى حدود عينة البحث والاسلوب الاحصائى المستخدم فقد تم التوصل الى الاستخلاصات الاتية:ا-ســتخدام تمرينـات TABATA حقـق نتائج افضـل لعينـة المجموعـة التجربييـة مـن استخدام التمرينـات التقليديـة للمجموعة الضـابطة فى المتغيرات البدنية (التوافق والقدرة والرشـاقة والمرونة والتوازن والقوة) ومستوى الاداء المهاري(وثبة النجمة- وثبـة الموزة- وثبة الليب-الميزان الامامي -ميزان الركبة-الدوران بالقدمين -دوران باسية) فى التمرينات الفنية لطالبات كليه التربية الرياضية بجامعة المنصورة. ץ-برنـامج تمرينـات TABATA المقترح ادى الى حدوث تحسـن واضـح وملحوظ فى المتغيرات البدنية (التوافق والقدرة والرشاقة والمرونة والتوازن والقوة)ومستويات الاداء المهارى(وثبة 
النجمة-وثبة الموزة-وثبة الليب-الميزان الامامي_-ميزان الركبة-الدوران بالقدمين-دوران باسية) بالنسبة للمجموعة التجريبية.

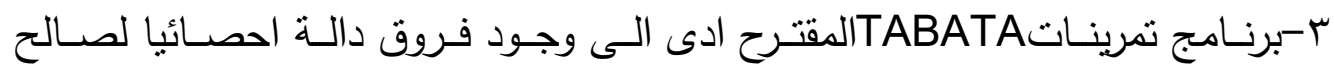
المجموعة التجريبية مقارنـة بنتائج المجموعة الضـابطة للبرنـامج التقليدى فى المتغيرات البدنية

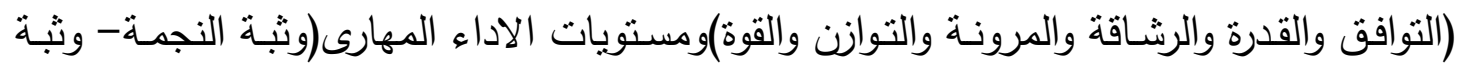
الموزة- وثبة الليب-ميزان أمامي-ميزان ركبة-دوران تقاطع القدمين-دوران باسية). التوصيات : الت فى ضوء استخلاصات البحث يمكن ان نوصى بما يلى:-

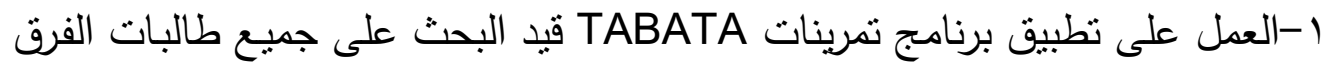

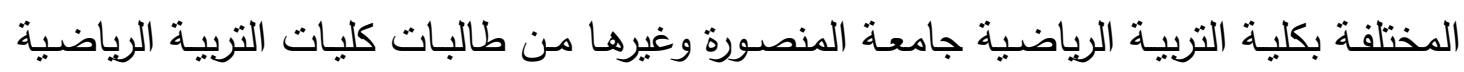

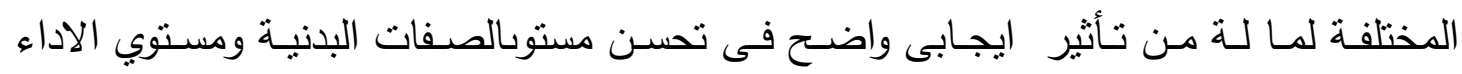

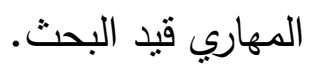

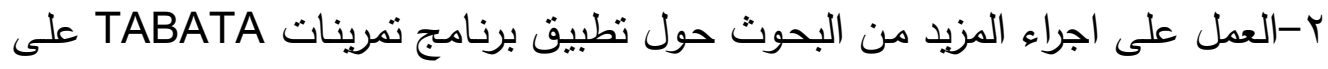

باقى الانشطة الرياضية المختلفة.

ب-العمل على تطبيق برنامج تمرينات TABATA لتتمية عناصر اللياقة البدنية المختلفة على باقى المهارات الأساسية والفنية فى التمرينات الفنية الإيقاعية.

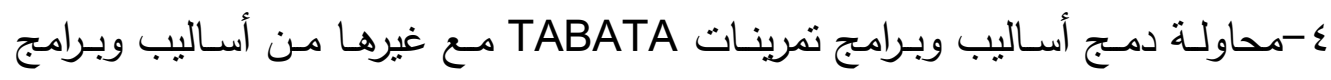

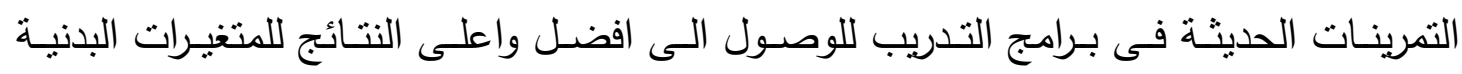
والمهارية فى التمرينات الفنية الإيقاعية وفى مختلف الأنشطة الرياضية الاخرى.

قائمة المراجع المراجع العربية

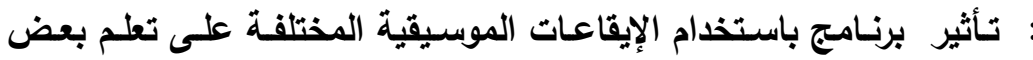

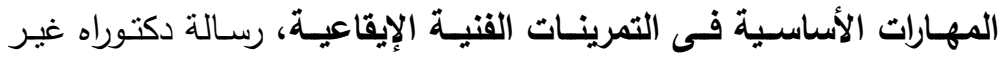

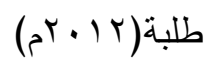

منشورة، كلية التربية الرياضية، جامعة المنصورة.

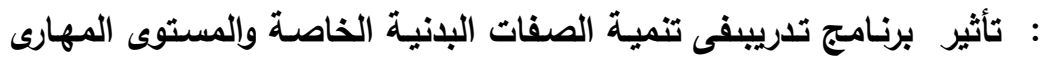
لوثبتى الفجوة والحلقة، رسالة ماجستير غير منشورة، كلية التربية الرياضية

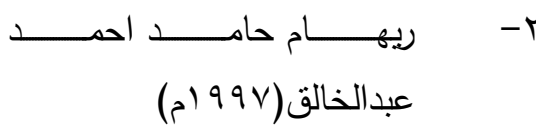

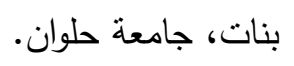

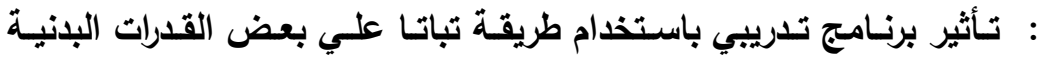

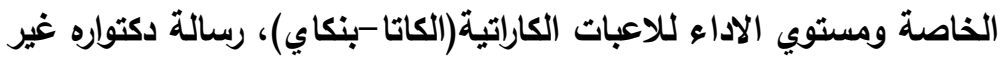

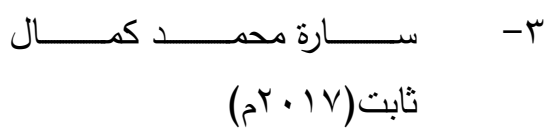
منشورة،كلية التربية الرياضية للبنات،جامعة حلوان. 
: مقدمة فى التمرينات الإيقاعية والجمباز الإيقاعى(المفاهيم العلمية والقنية)،

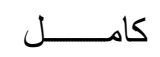

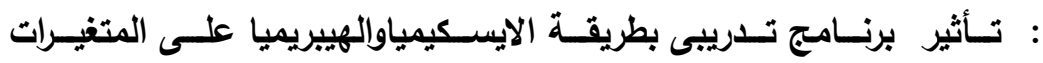
المصاحبة لمستوى اداء بعض الوثبات فى التمرينات، رسالة دكتوراة، كلية

b

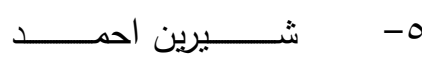

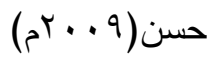

\section{التمرينات للبنات، طهية، دار المعارف للبنات، جامعة الزقازيق. التربية الرياضية للبنات، جامعة الزقازيق.}

: :

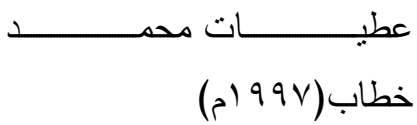

عنايـات على لبيـب وبيركسـان $-V$

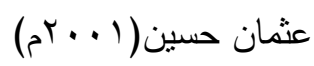
: التمرينـات الإيقاعيـة (الجمبـاز الإيقـاعى) والعـروض الرياضسية، دار الفكر عنايـات محمد فرج وفـاتن طـه العربى للنشر ، القاهرة.

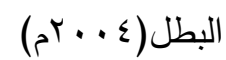
: المبادئ والأسس العلمية للتمرينات البدنية والعروض الرياضية، دار الوفاء للنشر ، الإسكندرية. : : علم النفس الرياضى، دار المعارف، طه، القاهرة. 1. - - محمد حسن علاوى(994) التقويم والقياس(نظريات وتطبيقات)، مكتبة 7 اكتوبر ، المنصورة. $:$

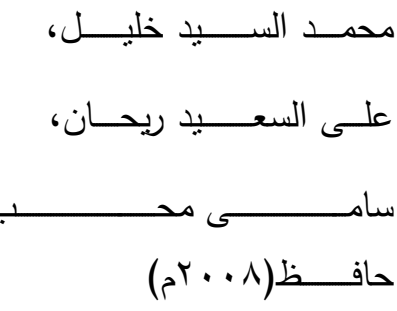

اختبارات الأداء الحركى، طس، دار الفكر العربى، القاهرة.

$$
\begin{aligned}
& \text { : محمد حسن علاوى، محمد } \\
& \text { نصرالدين رضوان( ( . . بم) }
\end{aligned}
$$

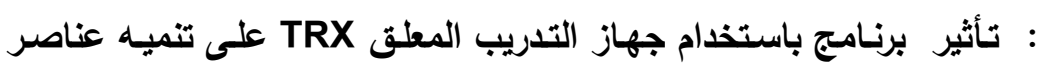
اللياقة البدنية الخاصة ببعض المهارات الهجومية للاعبات كرة السلة،رسالة ماجستير غير منشورة، كلية التربية الرياضية للبنات، جامعة حلوان.

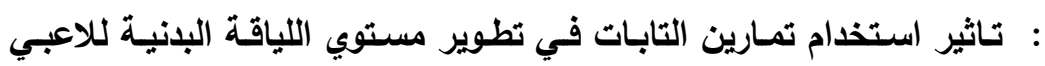

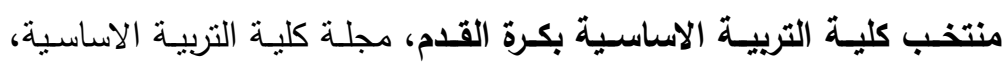

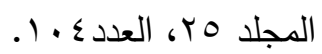

: القياس والتقويم فى التربية البدنية والرياضة، طع،الجزء الأول، دار الفكر العربى للنشر ، القاهرة.

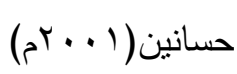
الاختبار الاورويى للياقة البدنية يوروفيت، مطبعة الإشعاع الفنية، : مصطفى السايح محمد، صلاح الإسكندرية. أنس محمد) (.... ( 


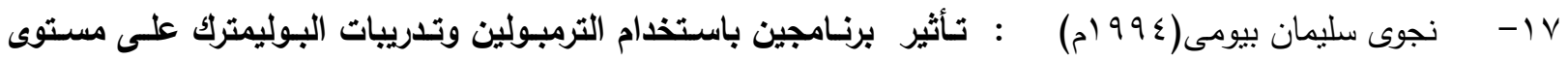

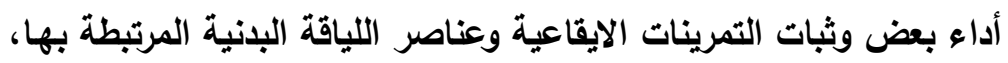

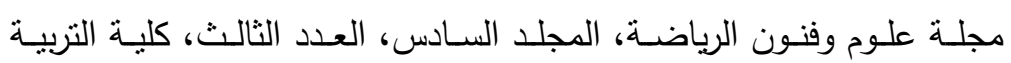
الرياضية للبنات بالجزيرة جامعة حلوان.

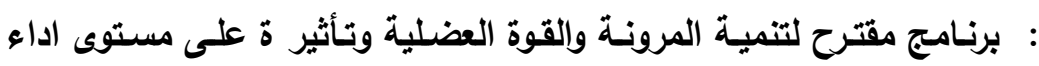

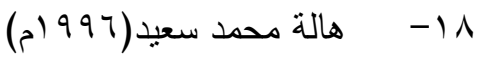
بعض الوثبات في التمرينـات الحديثة، رسالة ماجستير غير منشورة، كلية التربية الرياضية للبنات، جامعة الزقازيق.

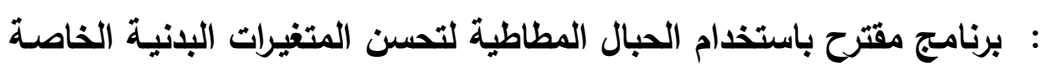

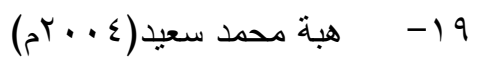

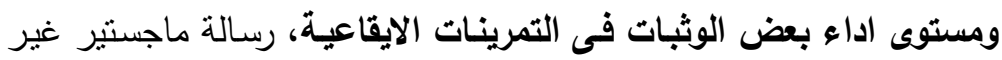
منشورة، كلية التربية الرياضية بنات، جامعة الزقازيق.

: تأثير برنامج باستخدام تمرينات التاباتا علي تطوير مستوي الاداء الخططي

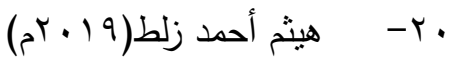

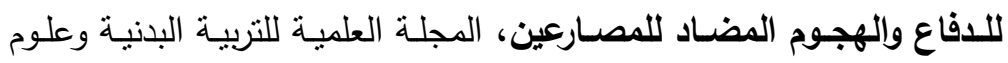
الرياضة، كلية التربية الرياضية للبنين جامعة حلوان،العدد 17.

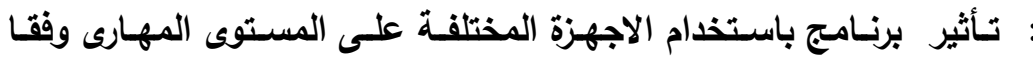

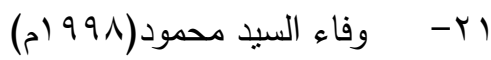
لمراحل الاداء الحركى الامثل لبعض الوثبـات فى التمرينات، رسالة دكتوراة غير منشورة، كلية التربية الرياضية للبنات، جامعة الزقازيق.

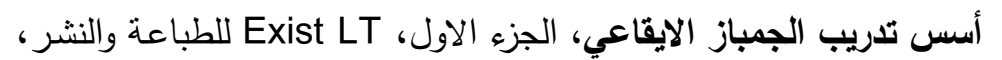
الاسكندرية.

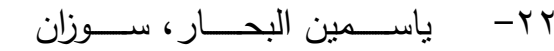

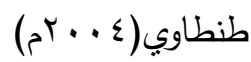

\section{المراجع الاجنبية}

23- Emberts,T.,Porcari,J.,Dobers-ten,S.,Steffen,J.,\&Foster,C2013.: Exercise intensity and energy expenditure of a tabata workout, Journal of sport science \& medicine, $12(3) 612$.

24- Federation Internationale De Gymnastique2017: Aerobic Gymnastics,January.

25Foster,C.,Farland,C.V.,Guidotti,F.,Harbin,M.,Roberts,B.,Schuette,J.,\&Porcar i,J.P,2015.-: The effects of high intensity inverval training vs steady state training on aerobic and anaerobic capacity, Journal of sport science\& 
medicine, $14(4) 747$.

$26-$

IzumiTabata,KoujiNishimur,MotokiKouzaki,YuusukeHiral,FutoshiOgita,Motohiko Miyachi,Kaoru Yamamoto1996: Effects of moderate-intensity endurance and high-intensity intermittent training on anaerobic capacity and VO(2max), Medicine \& Science in Sport \& Exercise, V.28(10), p 13271330,Oct.

27- Fortener,H.A.,Salgado,J.M.,Holmstrup,A.M.,\&Holmstrup,M.E2014.: Cardiovascular and metabolic demads of the kettlebell swing using tabata interval versus atraditional resistance protocol,Internationaljournalof exercise science, $7(3) 179$,.

28- Michael J. Rebold, Mallory S. Kobak,Ronald Otterstetter2013: The Influence Of a Tabata Interval Training Program Using An Aquatic Underwater Treadmill On Various Performance Variables,Department of Sports Science and Wellness, The University of Akron,Ohio,J Strength Cond Res, V.27(12),P3419-3425,Dec.

29- Olson,M2013.: Tabata interval exercise,Energy expenditure and post-exercise responses,Med Sci Sports Exerc,45,S420,.

30- Porcari John2013: Exercise Intensity and Energy Expenditure of a tabataWorkout,Journal of Sports Science and Medicine,University of Wisconsin,USA,V.12(3).P612-613.Sep

الشبكة الاولية للمعلومات 


\section{مستخلص البحث}

تأثثر برنامج باستخدام تمرينات TABATA على تنمية اللياقة البذنية الخاصة

ومستوى أداء بعض المهارات الأساسية في التمرينات الفنية

أ.م.د/ فاطمه محمود عبدالسميع غريب

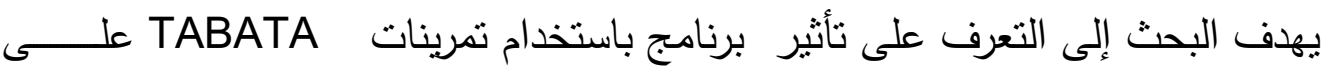

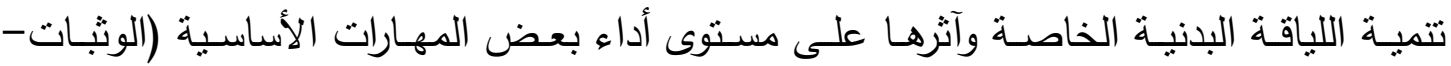

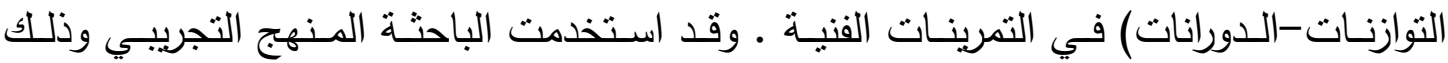
باستخدام التصميم التجريبي لمجموعتين إحداهما تجريبية والأخرى ضابطة، وبواسطة القياسين (القبلي - البعدي) لكل مجموعة، وقد بلغ حجم العينة (بسطالبة)، وتم تقسيمهن إلى مجموعنين قوام كل مجموعة (7 1 ( طالبات)، وأثنارت أهم النتائج الى تفوق المجموعة التجريبية المستخدمة

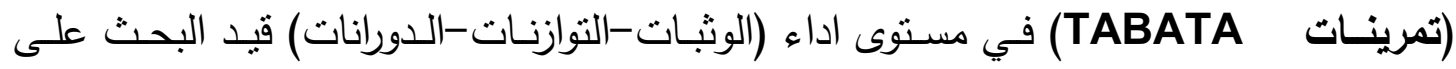
المجموعة الضابطة المستخدمة (التمرينات النقليدية). وأوصـت الباحثـة بمراعـاة الاسـتفادة مـن تمرينـات TABATA وتطبيقهـا في كليـات التربيـة الرياضية، كما أوصت أيضا بنطبيقها في مختلف الانشطة الرياضية.

\section{Abstract \\ The effect of a program Using TABATA exercise on the development of Special Fitness and its impact on the level performance for some skills rhythmic gymnastic}

\section{Dr. Fatima Mahmoud Abdel Sami Gharib}

The research aims to The effect of a program Using TABATA exercise on the development of Special Fitness and its impact on the level performance for some skills rhythmic gymnastics . the researchers used the experimental method using the experimental design of two experimental one and the other officer, and by the two measurements (tribal - post test) for each group. the total sample size (32 students), were divided into two groups, each group (16 students), important results to exceed the experimental group (Total body Resistance Exercises Tabata) leapsbalance-pivot in performance level under the control group (traditional exercise). The researcher recommend taking into account the benefit from the exercises overall resistance of the body Tabata and applied in the faculties of sports Education, as also recommend to apply in various sports activities. 